\title{
Can stable isotopes from tree rings improve our understanding of past variability in the southern annular mode?
}

\author{
Zachary Grzywacz \\ West Virginia University, ztg0004@mix.wvu.edu
}

Follow this and additional works at: https://researchrepository.wvu.edu/etd

Part of the Climate Commons, and the Physical and Environmental Geography Commons

\section{Recommended Citation}

Grzywacz, Zachary, "Can stable isotopes from tree rings improve our understanding of past variability in the southern annular mode?" (2021). Graduate Theses, Dissertations, and Problem Reports. 10257. https://researchrepository.wvu.edu/etd/10257

This Thesis is protected by copyright and/or related rights. It has been brought to you by the The Research Repository @ WVU with permission from the rights-holder(s). You are free to use this Thesis in any way that is permitted by the copyright and related rights legislation that applies to your use. For other uses you must obtain permission from the rights-holder(s) directly, unless additional rights are indicated by a Creative Commons license in the record and/ or on the work itself. This Thesis has been accepted for inclusion in WVU Graduate Theses, Dissertations, and Problem Reports collection by an authorized administrator of The Research Repository @ WVU. For more information, please contact researchrepository@mail.wvu.edu. 
Can stable isotopes from tree rings improve our understanding of past variability in the southern annular mode?

\title{
Zachary Grzywacz
}

Thesis submitted

to the Eberly College of Arts and Sciences

at West Virginia University

in partial fulfillment of the requirements for the degree of

Master of Arts in Geography

\author{
Amy Hessl, Ph.D., Chair \\ Shikha Sharma, Ph.D. \\ Kevin Anchukaitis, Ph.D. \\ Department of Geology \& Geography
}
Morgantown, West Virginia
2021

Keywords: stable isotopes, oxygen, tree rings, dendrochronology, Southern Hemisphere Copyright 2021 Zachary Grzywacz 


\begin{abstract}
Can stable isotopes from tree rings improve our understanding of past variability in the southern annular mode?
\end{abstract}

\title{
Zachary Grzywacz
}

Few annually dated stable isotope records exist across Oceania. In mid- to high-latitude locations in South America, tree-ring stable isotopes provide information about past climate dynamics such as the Southern Annular Mode (SAM). The SAM drives latitudinal shifts in Southern Hemisphere westerly winds, influencing temperature and moisture delivery across the mid- to high-latitudes, including Tasmania. Combinations of paleoclimate proxies from across the Southern Ocean might provide insight into dynamic processes like the SAM that are difficult to measure with a single proxy. Measuring stable carbon and oxygen isotope ratios from tree rings in Tasmania could provide complementary data to contribute to existing reconstructions heavily reliant on tree ring width chronologies.

A team collected tree core samples of Athrotaxis selaginoides from a high elevation site in Tasmania, Australia. The site receives abundant rainfall throughout the year and is $\sim 130 \mathrm{~km}$ from the Global Network of Isotopes in Precipitation (GNIP) site at Cape Grim. I crossdated our new samples against an existing tree-ring width chronology (439 BCE - 2011 CE) and analyzed the $\delta^{13} \mathrm{C}$ and $\delta^{18} \mathrm{O}$ from the individual rings of ten trees for the period $1960-2018$. Using high resolution (0.25 degrees) Australian Bureau of Meteorology Scientific Information for Land Owners (BOM SILO) climate data and ECMWF ERA5 reanalysis data, I disentangled the effects of local climate and source region on the isotopic signatures recorded in the annual rings. In addition, I used HYSPLIT backward trajectory analysis to determine the source region of precipitation to Mount Read and whether the source region is influenced by the SAM.

Median $\delta^{18} \mathrm{O}_{\mathrm{TR}}(\mathrm{n}=10)$ is correlated with temperature and vapor pressure deficit in the early growing season. In addition, spatial correlations reveal that median $\delta^{18} \mathrm{O}_{\mathrm{TR}}$ is positively correlated with temperature and negatively correlated with precipitation in the source region. However, measurements of $\delta^{18} \mathrm{O}_{\mathrm{TR}}$ exhibit high inter-tree variation, particularly between 1960 1990. Suess-corrected $\delta^{13} \mathrm{C}_{\mathrm{TR}}$ measurements are not significantly correlated with local climate measures, and have no significant relationship with $\delta^{18} \mathrm{O}_{\mathrm{TR}}$, implying that the influence of local moisture on the isotopic signatures is weak. During positive states of the SAM, there is a midlatitude influence in the source region of precipitation to Mount Read that is not present in negative states of the SAM. Our results indicate that combined $\delta^{18} \mathrm{O}_{\mathrm{TR}}$ and $\delta^{13} \mathrm{C}_{\mathrm{TR}}$ proxies may provide additional information about past moisture conditions during the growing season, potentially contributing to more robust reconstructions of the SAM; however, additional sampling in a different environment may be necessary to resolve inter-tree variation in $\delta^{18} \mathrm{O}_{\mathrm{TR}}$. 


\section{Table of Contents}

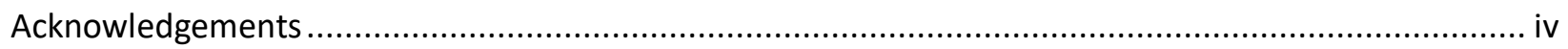

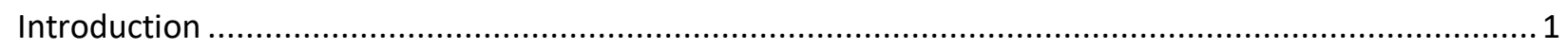

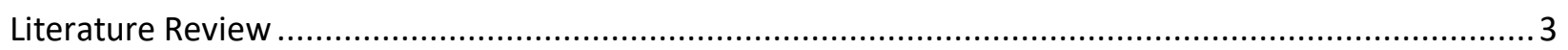

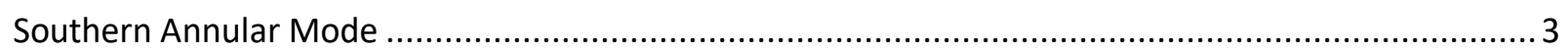

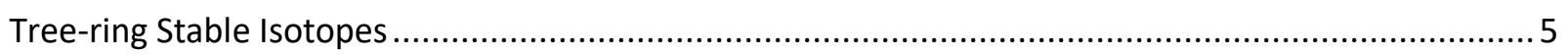

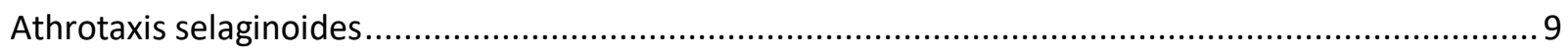

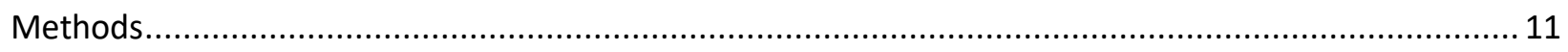

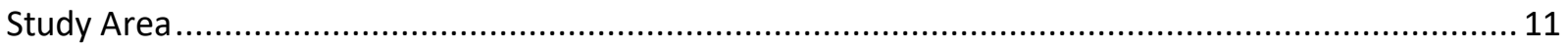

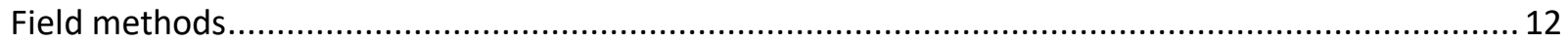

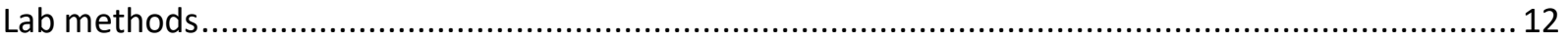

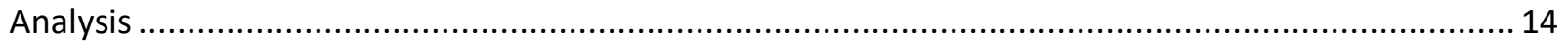

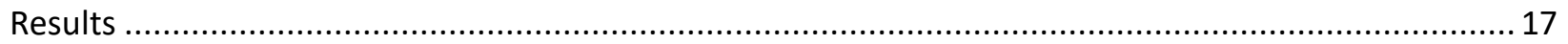

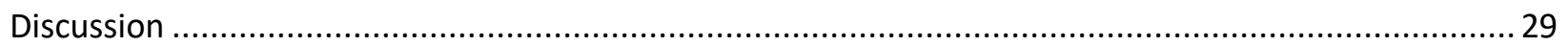

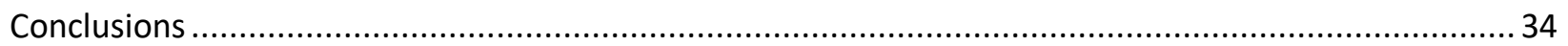

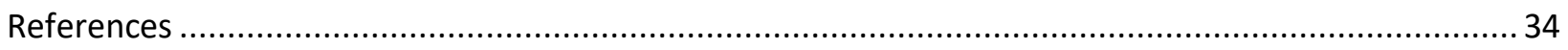

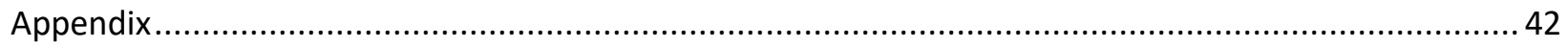




\section{Acknowledgements}

I would like to begin by thanking my advisor, Dr. Amy Hessl. I am incredibly grateful for Dr. Hessl's guidance and support during every step of this project. She has been a wonderful teacher and mentor, and I wouldn't have been able to perform this research if she hadn't offered me the opportunity to work in her lab. I would also like to thank my other committee members, Dr. Shikha Sharma and Dr. Kevin Anchukaitis, for their involvement with this research.

I would like to thank Dr. Michael Evans of the University of Maryland, for using his lab to perform isotope analysis on my samples and answering all of my questions about the process. I would also like to thank Scott Nichols for his help in collecting the tree cores at Mount Read. I must give thanks to Meagan Walker, Alexis Mueller, Ethan Cade, and Kayla Bailey for all of their hours in the lab spent working on the ring width chronology, sectioning cores, and offering their friendship. Thank you to Autum Downey for helping me out in the chemistry lab when I was performing cellulose extractions. I would also like to thank the West Virginia University Department of Geology and Geography for providing the equipment and workspace necessary to perform this research.

Finally, I must thank my friends and family for their unwavering support. To the friends I made in Morgantown, including my peers in the Geography department, I will always cherish the time that we were able to spend together and I wish that it could have lasted longer. To my parents, Tom and Traci, thank you for putting me in a position to succeed and believing in me every step of the way. To my partner, Heather, I have no words that can accurately describe the incredible level of support you've given me in all aspects of my life. Thank you for giving me strength, reminding me to rest, and listening to me talk about some trees that sit on a mountain on the other side of the planet.

This material is based upon work supported by the National Science Foundation under Grant No. 1804121. 


\section{Introduction}

The southern annular mode (SAM) is a latitudinal pressure gradient that controls the strength and position of the Southern Hemisphere westerly winds. In turn, this pressure gradient influences climate variability, including temperature, precipitation, and humidity in the Southern Hemisphere at decadal-to-centennial scales. Previous paleoclimate reconstructions combined with instrumental data and model experiments suggest that the SAM has entered an increasingly positive state since the late 1400s (Abram et al. 2014, Villalba et al. 2012, Zhang et al. 2010). This trend has likely contributed to changing environmental conditions in the mid-latitudes, including increased drought and fire activity in southern Australia (Mariani \& Fletcher, 2016). The long-term context of this trend in SAM remains uncertain. Southern Hemisphere climate data for periods beyond the instrumental record are limited (Allen et al., 2017) and there is disagreement among the existing reconstructions regarding the multi-decadal behavior of the SAM (Hessl et al., 2017).

Tree ring data provide a source of high-resolution millennial-length climate information for the Southern Hemisphere and have improved our understanding of variability in dynamical processes like the SAM (Trouet et al., 2009). Several multi-millennial tree ring records exist for the Southern Hemisphere (Cook et al., 1991; Allen et al., 2017; Boswijk et al., 2006; Lara \& Villalba, 1993), yet there has been limited application of tree ring stable isotopes for climate reconstruction in the Southern Hemisphere (Pearman et al., 1976, Lavergne et al., 2016; Roig et al., 2006). Oxygen isotopes in tree rings $\left(\delta^{18} \mathrm{O}_{\mathrm{TR}}\right)$ are a promising source of information about past climate, though the effects of precipitation source region, local climate, and tree physiology on $\delta^{18} \mathrm{O}_{\mathrm{TR}}$ can be complex (McCarroll and Loader, 2004; Treydte et al., 2014; Porter et al., 2014).

Generally, oxygen isotopes in tree rings follow distinct trends for temperature and precipitation. Greater temperatures and evaporation typically result in more enriched $\delta^{18} \mathrm{O}_{\mathrm{TR}}$ signals through influencing the $\delta^{18} \mathrm{O}$ of the source water (precipitation) and increasing evaporative enrichment (Dansgaard, 1964). Precipitation amount generally has a negative relationship with $\delta^{18} \mathrm{O}_{\mathrm{TR}}$, due to Rayleigh distillation. However, these effects can also be influenced by source region (a polar source region will be more depleted, and vice versa for tropical source regions) and seasonal effects (higher temperatures mean an enriched $\delta^{18} \mathrm{O}$ signal in the summer; source region may change with the seasons). Local moisture and the origin of air masses are often the strongest influences on the $\delta^{18} \mathrm{O}_{\mathrm{TR}}$ chronology (Meier et al., 2020; McCarroll and Loader, 2004; Treydte et al., 2014).

Dual isotope methods might also serve to reduce uncertainty around the complex processes influencing $\delta^{18} \mathrm{O}_{\mathrm{TR}}$ (Scheidegger et al., 2000; Roden \& Farquhar, 2012). Carbon isotopes $\left(\delta^{13} \mathrm{C}_{\mathrm{TR}}\right)$ are influenced by both stomatal conductance and photosynthetic rate, while, of those two factors, oxygen isotopes are only influenced by stomatal conductance. $\delta^{13} \mathrm{C}_{\mathrm{TR}}$ is often negatively associated with relative humidity, which controls stomatal conductance, and positively associated with irradiance, which influences photosynthetic rate (Gagen et al., 2004; McCarroll and Pawellek, 2001). These relationships allow us to distinguish which processes are dominant at the site given the combination of both measurements. For example, a positive 
relationship between $\delta^{18} \mathrm{O}_{\mathrm{TR}}$ and $\delta^{13} \mathrm{C}_{\mathrm{TR}}$ implies strong stomatal control over the signal of both isotopes (Scheidegger et al., 2000).

Assuming that there is a strong relationship between the $\delta^{18} \mathrm{O}$ of precipitation $\left(\delta^{18} \mathrm{O}_{\mathrm{P}}\right)$ and $\delta^{18} \mathrm{O}_{\mathrm{TR}}$, it is possible to reconstruct historical temperature variations using $\delta^{18} \mathrm{O}_{\mathrm{TR}}$ (Treydte et al., 2014). In South American mid-latitude sites, $\delta^{18} \mathrm{O}_{\mathrm{TR}}$ has a positive relationship with summer temperature (Lavergne et al., 2016; Roig et al., 2006), though more research is needed to determine if this relationship is present at other Southern Hemisphere sites. Expanding the use of this method to new tree species and different regions would bolster the ability of this proxy to contribute to Southern Hemisphere climate reconstructions.

Tasmania, Australia $\left(39-42^{\circ} \mathrm{S}\right)$ is located at the northern extent of the current position of the SAM, making it an ideal location to develop paleoclimate proxies for supporting reconstructions of the SAM. Athrotaxis selaginoides, a conifer endemic to Tasmania, is long-lived with some individuals persisting for 1000 years or more, and subfossil wood suggesting preservation of up to 2000 years (Allen et al., 2017). A. selaginoides develops consistent annual rings, but ring widths only weakly reflect local climate variability (Allen et al., 2017), indicating that stable isotope records may contribute new climate information that is not present in other tree-ring parameters. Mount Read, located on the west coast of Tasmania, averages over $3500 \mathrm{~mm}$ of precipitation per year. Temperatures at high elevation $(1100 \mathrm{~m}$, in the case of Mt. Read) (Wilson et al., 2011) are relatively low, which would reduce the effect of fractionation via evaporation from the soil surface (Table 1).

Given the location of the site and expected relationships for $\delta^{18} \mathrm{O}_{\mathrm{TR}}$ observed at other sites (Porter et al., 2014; Lavergne et al., 2016; Meier et al., 2020; Table 1), I tested the following hypotheses:

$\mathrm{H} 1$ : At the local scale, $\delta^{18} \mathrm{O}_{\mathrm{TR}}$ in $\mathrm{KBP}$ tree rings is positively correlated with local temperature and negatively correlated with precipitation and relative humidity during the growing season.

$\mathrm{H}$ 2: At the local scale, $\delta^{13} \mathrm{C}_{\mathrm{TR}}$ in KBP tree rings is positively correlated with irradiance and negatively correlated with precipitation and relative humidity during the growing season.

$\mathrm{H} 3$ : At the regional scale, $\delta^{18} \mathrm{O}_{\mathrm{TR}}$ in $\mathrm{KBP}$ tree rings is positively correlated with temperature and evaporation and negatively correlated with precipitation in the source region (as defined by splitR backward trajectory analysis) in September - February.

H4: Pathways of moisture delivery to Mount Read will be dependent on the state of the SAM. 
Table 1: Summary of expected $\delta^{18} O_{T R}$ and $\delta^{13} C_{T R}$ relationships with local and regional climate

\begin{tabular}{|c|c|}
\hline Enriched $\boldsymbol{\delta}^{\mathbf{1 8}} \mathbf{O}_{\text {TR }}$ signal & Depleted $\boldsymbol{\delta}^{\mathbf{1 8}} \mathbf{O}_{\text {TR }}$ signal \\
\hline Local temperature increased & Local temperature decreased \\
Local RH/precipitation decreased & Local RH/precipitation increased \\
Increased evaporative enrichment & Decreased evaporative enrichment \\
Source moisture more enriched & Source moisture more depleted \\
Lower latitude moisture source (25-35 & Higher latitude moisture source (Southern \\
degrees South) & Ocean) \\
& \\
\hline
\end{tabular}

\begin{tabular}{|c|c|}
\hline Enriched $\boldsymbol{\delta}^{\mathbf{1 3}} \mathbf{C}_{\mathbf{T R}}$ signal & Depleted $\boldsymbol{\delta}^{\mathbf{1 3}} \mathbf{C}_{\mathbf{T R}}$ signal \\
\hline High photosynthetic rate & Low photosynthetic rate \\
Low stomatal conductance & High stomatal conductance \\
High irradiance & Low irradiance \\
Low precipitation/RH & High precipitation/RH \\
& \\
\hline
\end{tabular}

\section{Literature Review}

\section{Southern Annular Mode}

The SAM is defined as the leading mode of variability of the mid-latitude Southern Hemisphere pressure field (Thompson \& Wallace, 2000; Marshall, 2003). The change in the SAM that is most influential in driving climate conditions is the latitudinal movement of the Southern Hemisphere mid-latitude jet, which drives atmospheric conditions such as temperature, surface pressure, and zonal wind. When the SAM is in a positive phase, the jet and its associated storm tracks shift towards Antarctica. While the SAM is in a negative phase, the shift moves in the opposite direction, towards the equator. During the period of instrumental record ( $\sim 1950$ to present), the SAM has shifted to a positive phase, as measured by increases in latitudinal sea level pressure. This trend is associated with increased drought and fire activity in the midlatitudes of the Southern Hemisphere continents (Mariani \& Fletcher, 2016).

Several factors may be responsible for the recent positive trend in the SAM. Foremost among these are ozone depletion and global warming caused by increased greenhouse gas emissions in the modern era (Kushner et al., 2001). However, reconstructions of Southern Hemisphere conditions suggest that the positive trend in the SAM has been present since the $15^{\text {th }}$ century, implying that natural forcing (particularly increased solar irradiation) may be contributing to the positive shift (Abram et al., 2014). By observing historical trends in the SAM, it is possible to understand its natural variation, which will provide insight into how natural and anthropogenic factors interact to generate both the recent positive shift as well as the strong negative excursion in the late 1300 s to early 1400 s.

Interannual to centennial scale variability in the SAM could be generated by its interaction with other oceanic or atmospheric dynamics. For example, when different phases of the SAM and 
ENSO align, Fogt et al. (2011) observed extreme wind anomalies in the Southern Pacific Ocean. There is also evidence that the Antarctic polar vortex interacts with the SAM at a seasonal scale (Lim et al., 2019). When the Antarctic polar vortex weakens, it can influence the SAM to enter an anomalously negative state at the monthly scale, a trend which has been linked to extreme hot and dry conditions in Australia. The Interdecadal Pacific Oscillation (IPO) has been linked to Australian megadroughts in its positive phase (Vance et al., 2015). Coinciding phases of the SAM and the IPO could produce strong drought conditions in Australia.

The SAM has zonally distinct effects on climate across the mid- to high- latitudes of the Southern Hemisphere. Sea level pressure presents an exception to this variation, as SAM correlations with SLP are consistent and annular in nature (Marshall, 2003). In southern Australia (including Tasmania), the SAM is negatively correlated with precipitation in the winter months (Hendon et al., 2007). As the SAM has shifted to a positive state, there has been an associated decline in precipitation in the winter (Cai et al., 2011). However, this relationship reverses in the summer months, albeit with a weaker association (Hessl et al., 2017). These effects are not universal for the entire Southern Hemisphere, or even across the same latitudes. A different trend is consistent with patterns in South America, where the SAM index is wellcorrelated with summer precipitation, but not winter precipitation (Garreaud et al., 2013). These zonally distinct effects pose significant challenges for hemispheric-scale reconstructions of SAM variability.

Three of the existing SAM reconstructions (Dätwyler et al., 2018; Abram et al., 2014; Villalba et al., 2012) tend to agree over multi-decadal to centennial scale trends, such as the positive trend in the modern era and the negative excursion in the $15^{\text {th }}$ century. This negative excursion is the result of a century-long decrease that peaks as late as 1480, though the amplitude is debatable and may range between -1 and -2.8 (Dätwyler et al., 2018). Zhang et al. (2010) attempted to remove all centennial scale variability, and as such there are no long-term trends visible in the reconstruction. Limited data are available prior to 1000 C.E., and none of the models go back further than this as a result. Among all of the reconstructions, there is disagreement about shortterm, decadal scale trends. This could be caused by seasonal or spatial variability in the SAM.

SAM reconstructions have some limitations, based on the location and nature of readily available data. Because many proxies record growing season conditions, winter months are not included in many reconstructions. This may not be an issue for reconstructions of summer SAM, but the abundance of these records in annual reconstructions may present a strong seasonal bias. Overall, the SAM index performs poorly in correlating with spring and winter conditions (Jones et al., 2009). Targeting proxies that are known to capture temperature or precipitation for seasons other than summer would increase the strength of SAM reconstructions for these months, thus increasing the strength of annual reconstructions as well. In addition, the Indian Ocean presents a challenge for reconstructing the SAM due to limited land area and a sparse proxy network (Hessl et al., 2017). Developing proxies that record conditions for this region would greatly increase knowledge of the spatial variability of the SAM. Finally, the climatic effects of the SAM are asymmetrical, which challenges the traditional index that attempts to measure the entire Southern Hemisphere. Given variability between regions, it may be more beneficial to produce and compare regional reconstructions (Visbeck, 2009). This approach gives greater insight into 
spatial trends in the SAM without altering temporal resolution, though it does complicate the calculation of Hemisphere-wide trends over time.

\section{Tree-ring Stable Isotopes}

Dendrochronology has been used for a variety of scientific purposes, including paleoclimatology. Many trees produce annual rings, due to slower, denser cell growth at the end of the growing season each year. Each ring typically represents one year of growth, and the outermost ring represents either the year that the sample was gathered (in the case of a live tree) or the year that the tree stopped growing. This seasonal pattern of growth makes it possible to track a tree's growth over time using a cross-section or core of the tree (Stokes \& Smiley, 1968). Crossdating makes it possible to assign each ring to an absolute year. The process of crossdating compares patterns of ring width to match growth years for different trees and determine specific years for each ring (Speer, 2010). Tree ring width and other wood properties are used in climatology to measure climate variability over time. Trees that exist at the edge of their species' ecological amplitude may have their radial growth limited by factors such as temperature or drought (Fritts, 1976). If the rings of these trees vary with changing growth conditions, then these trees exhibit sensitivity and can be used to measure the variation of the limiting factor (often temperature or precipitation) over time. If these records are standardized using methods such as age band decomposition, they can be compiled and used to create hemisphere-wide reconstructions of climatic conditions (Speer, 2010).

Tree rings have further potential with the application of stable isotopes, particularly where ring width variables are weakly correlated with climate variables (McCarroll and Loader, 2004). Principles from dendrochronology and stable isotope theory can be combined to produce climate proxies using the isotopic composition of tree rings (Libby et al., 1976). Trees record the conditions in the environment around them by taking in elements from the soil and the atmosphere. Thus, in the absence of translocation between rings, the wood of a tree represents a record of isotopic history. Tree-ring isotopes have many of the same advantages that tree-ring width chronologies provide - the rings produce a perfect annual resolution record and the abundance of trees that overlap in time provides the ability to determine the variability of the measurements (McCarroll and Loader, 2004). However, unlike radial growth, which is determined by a variety of factors, the environmental controls on isotope ratios in tree rings are relatively definite, meaning that tree-ring isotopes may be more likely to represent a climatic signal. Lukač et al. (2021) demonstrated that the tree-ring isotope records of the species Pinus heldreichii produced stronger climate reconstructions than the ring width record of the same species.

Elements taken up by trees are fractionated at a several points along their paths to allocation in wood. Therefore, the isotopic ratios recorded in the rings are not directly representative of the source water or air - though under the right conditions, they reflect the variation in these values (Treydte et al., 2014). Because of this, there is added value to tree-ring isotope measurements, as they also record how the tree responded to changing environmental conditions. This also complicates the analysis that must be done to understand the signals found in tree-ring isotopes (McCarroll and Loader, 2004). 
Stable oxygen isotopes in precipitation have been used extensively to investigate global climate (Dansgaard, 1964). The lighter oxygen isotope $\left({ }^{16} \mathrm{O}\right)$ evaporates more readily than the heavier oxygen isotope $\left({ }^{18} \mathrm{O}\right)$, however ${ }^{18} \mathrm{O}$ condenses more readily than ${ }^{16} \mathrm{O}$. At higher temperatures, ${ }^{18} \mathrm{O}$ will more readily evaporate and form precipitation. Therefore, the isotopic composition of precipitation is dependent upon conditions in the source region of the moisture as well as local conditions where precipitation forms. The temperature-dependent nature of this relationship has made it possible to make inferences about past global temperatures based on the ratio of ${ }^{18} \mathrm{O}$ to ${ }^{16} \mathrm{O}$ from a variety of proxies across space and time.

In trees, oxygen is taken up through soil moisture $\left(\mathrm{H}_{2} \mathrm{O}\right)$ and follows a long path which includes multiple points of fractionation (Treydte et al., 2014). In some settings, $\delta^{18} \mathrm{O}$ of soil water reflects $\delta^{18} \mathrm{O}$ of local precipitation; however, several factors can modify this relationship. Evaporation can enrich the soil moisture in ${ }^{18} \mathrm{O}$, as ${ }^{16} \mathrm{O}$ evaporates more readily than ${ }^{18} \mathrm{O}$. In addition, the rooting depth of the tree can alter the residence time of water in the soil, as deeper-rooting trees may preferably use groundwater as opposed to surface moisture (Ehleringer \& Dawson, 1992). These two factors can interact to produce an isotopic signal that is more enriched than the original precipitation.

While source water composition is an important control on $\delta^{18} \mathrm{O}_{\mathrm{TR}}$, the other major source of fractionation occurs in the leaf, where water can be enriched through evaporation. Short-term variation in tree-water $\delta^{18} \mathrm{O}$ can be introduced by stomatal conductance, which is influenced by relative humidity, the dominant control on leaf evaporative enrichment. However, this process is tempered by the advective transport of unenriched xylem water to the leaf, producing a Péclet effect (Barbour et al. 2004). This process does not necessarily drive variation in $\delta^{18} \mathrm{O}_{\mathrm{TR}}$. If relative humidity is high, source water may be more dominant at a seasonal scale (Treydte et al., 2014).

Given these sources of fractionation, the most ideal case for paleoclimate reconstruction of $\delta^{18} \mathrm{O}_{\mathrm{P}}$ from $\delta^{18} \mathrm{O}_{\text {TR }}$ occurs when soil water reflects isotopic measurements of precipitation and where relative humidity is high, as this would imply that the isotopic composition of water taken into the tree is reflective of the precipitation. Sites with high annual precipitation are, therefore, wellsuited for studies involving oxygen isotopes in tree rings by reducing evaporative enrichment of soil water and reducing fractionation in the leaf (Treydte et al. 2014). In these sites, $\delta^{18} \mathrm{O}_{\mathrm{TR}}$ is likely to reflect that of the source water precipitation.

$\delta^{18} \mathrm{O}_{\mathrm{P}}$ is affected by a variety of factors. $\delta^{18} \mathrm{O}_{\mathrm{P}}$ is influenced by the temperature at which water vapor forms, and subsequently the temperature at which precipitation forms. As a result, there is a seasonal effect with oxygen isotopes, with summer precipitation often being more enriched in $\delta^{18} \mathrm{O}$ than colder seasons. Following the same rule, higher latitude moisture sources will be more depleted than those from low latitudes. Changes in atmospheric circulation can alter the source region of precipitation, thereby affecting the temperature where vaporization takes place (Edwards et al., 1996). In addition, changes in source region can alter the path that the moisture takes before raining out. The path that moisture takes before precipitating over a particular area can influence the number of rainouts that the vapor produces before reaching its destination, depleting later rainouts via Rayleigh distillation (Rozanski \& Sonntag, 1982). Thus, climate 
dynamics such as the SAM could alter the signal found in the $\delta^{18} \mathrm{O}_{\mathrm{TR}}$, and variation in the record may not represent variation in local climate (Porter et al., 2014). If the patterns of $\delta^{18} \mathrm{OP}_{\mathrm{P}}$ at the site (Mount Read) are reflective of trends in the source region, then observing $\delta^{18} \mathrm{O}_{\mathrm{P}}$ at the site could provide insight into climate dynamics such as the SAM. If this signal is preserved in the tree rings of A. selaginoides on Mount Read, it is possible to reconstruct nearly two millennia of climate history using stable isotope analyses.

Carbon isotopes provide a different measure to track local conditions than oxygen isotopes. While $\delta^{18} \mathrm{O}_{\mathrm{TR}}$ is influenced by both local and regional variables, $\delta^{13} \mathrm{C}_{\mathrm{TR}}$ is controlled by site-level processes. $\delta^{13} \mathrm{C}_{\mathrm{TR}}$ is sensitive to local moisture, similarly to $\delta^{18} \mathrm{O}_{\mathrm{TR}}$; however, $\delta^{13} \mathrm{C}_{\mathrm{TR}}$ is also sensitive to changes in photosynthetic rate, which do not affect $\delta^{18} \mathrm{O}_{\mathrm{TR}}$. As such, $\delta^{13} \mathrm{C}_{\mathrm{TR}}$ can support any relationship that $\delta^{18} \mathrm{O}_{\mathrm{TR}}$ has with moisture conditions or weaken confidence in that relationship if $\delta^{13} \mathrm{C}_{\mathrm{TR}}$ behaves differently than $\delta^{18} \mathrm{O}_{\mathrm{TR}}$.

The $\delta^{13} \mathrm{C}_{\mathrm{TR}}$ signal found in trees is dependent upon the ratio of the internal carbon concentration to the ambient carbon concentration (ci/ca). This ratio is influenced by two main processes: photosynthetic rate and stomatal conductance. A high photosynthetic demand results in a decrease in internal carbon, meaning that there is less discrimination by the plant when assimilating carbon. This results in a more enriched $\delta^{13} \mathrm{C}_{\mathrm{TR}}$ value. In addition, if stomata are closed, then the ratio of ci/ca will decrease, resulting in a similar effect to an increased photosynthetic rate - less carbon discrimination and enriched $\delta^{13} \mathrm{C}_{\mathrm{TR}}$ values incorporated into the tree. As a result, $\delta^{13} \mathrm{C}_{\mathrm{TR}}$ is influenced by factors that control stomatal conductance and photosynthetic rate. $\delta^{13} \mathrm{C}_{\mathrm{TR}}$ is often found to be negatively associated with relative humidity and positively associated with water stress, as these are factors that control stomatal conductance (Gagen et al., 2004). In addition, $\delta^{13} \mathrm{C}_{\mathrm{TR}}$ is often found to be positively related to irradiance, as this influences photosynthetic rate (McCarroll and Pawellek, 2001).

Analysis of $\delta^{18} \mathrm{O}_{\mathrm{TR}}$ and $\delta^{13} \mathrm{C}_{\mathrm{TR}}$ as paired measurements can provide insight into which processes are influential at the site (Moreno-Gutierrez et al., 2012). Scheidegger et al. (2000) outlined a process that uses dual isotope measurements to determine whether stomatal conductance or photosynthetic capacity cause differences in $\delta^{13} \mathrm{C}_{\mathrm{TR}}$. This is possible because while $\delta^{13} \mathrm{C}_{\mathrm{TR}}$ is influenced by both stomatal conductance and photosynthetic rate, $\delta^{18} \mathrm{O}_{\mathrm{TR}}$ is not influenced by photosynthetic rate, though has some sensitivity to stomatal conductance. Given paired $\delta^{18} \mathrm{O}_{\mathrm{TR}}$ and $\delta^{13} \mathrm{C}_{\mathrm{TR}}$ measurements, the relationship between $\delta^{18} \mathrm{O}_{\mathrm{TR}}$ and $\delta^{13} \mathrm{C}_{\mathrm{TR}}$ can indicate which processes are controlling these isotopic measurements. Change in relative humidity can be derived from the change in $\delta^{18} \mathrm{O}_{\mathrm{TR}}$, and the change in internal carbon concentration (ci) can be derived based on the change in $\delta^{13} \mathrm{C}_{\mathrm{TR}}$. These inferences are, however, dependent upon $\delta^{18} \mathrm{O}_{\mathrm{TR}}$ being reflective of changes in relative humidity, which may not be true at all sites (Roden $\&$ Farquhar, 2012).

Assuming that stomatal conductance is an influential factor for both $\delta^{18} \mathrm{O}_{\mathrm{TR}}$ and $\delta^{13} \mathrm{C}_{\mathrm{TR}}$, one may expect to see more enriched values of both isotopes when stomatal conductance is low. Given these relationships, it is implied that there would be a positive relationship between $\delta^{18} \mathrm{O}_{\mathrm{TR}}$ and $\delta^{13} \mathrm{C}_{\mathrm{TR}}$, as indicated in Figure 1. If this relationship is found to be true, then measures that influence stomatal conductance (such as local precipitation, relative humidity and vapor pressure 
deficit) are likely correlated with both $\delta^{18} \mathrm{O}_{\mathrm{TR}}$ and $\delta^{13} \mathrm{C}_{\mathrm{TR}}$. If this relationship is not found to be present, then it is possible that local moisture measures are only related to one (or neither) of $\delta^{18} \mathrm{O}_{\mathrm{TR}}$ and $\delta^{13} \mathrm{C}_{\mathrm{TR}} . \delta^{13} \mathrm{C}_{\mathrm{TR}}$ may be influenced mainly by photosynthetic rate, or $\delta^{18} \mathrm{O}_{\mathrm{TR}}$ may more closely reflect changes in $\delta^{18} \mathrm{O}_{\mathrm{P}}$.

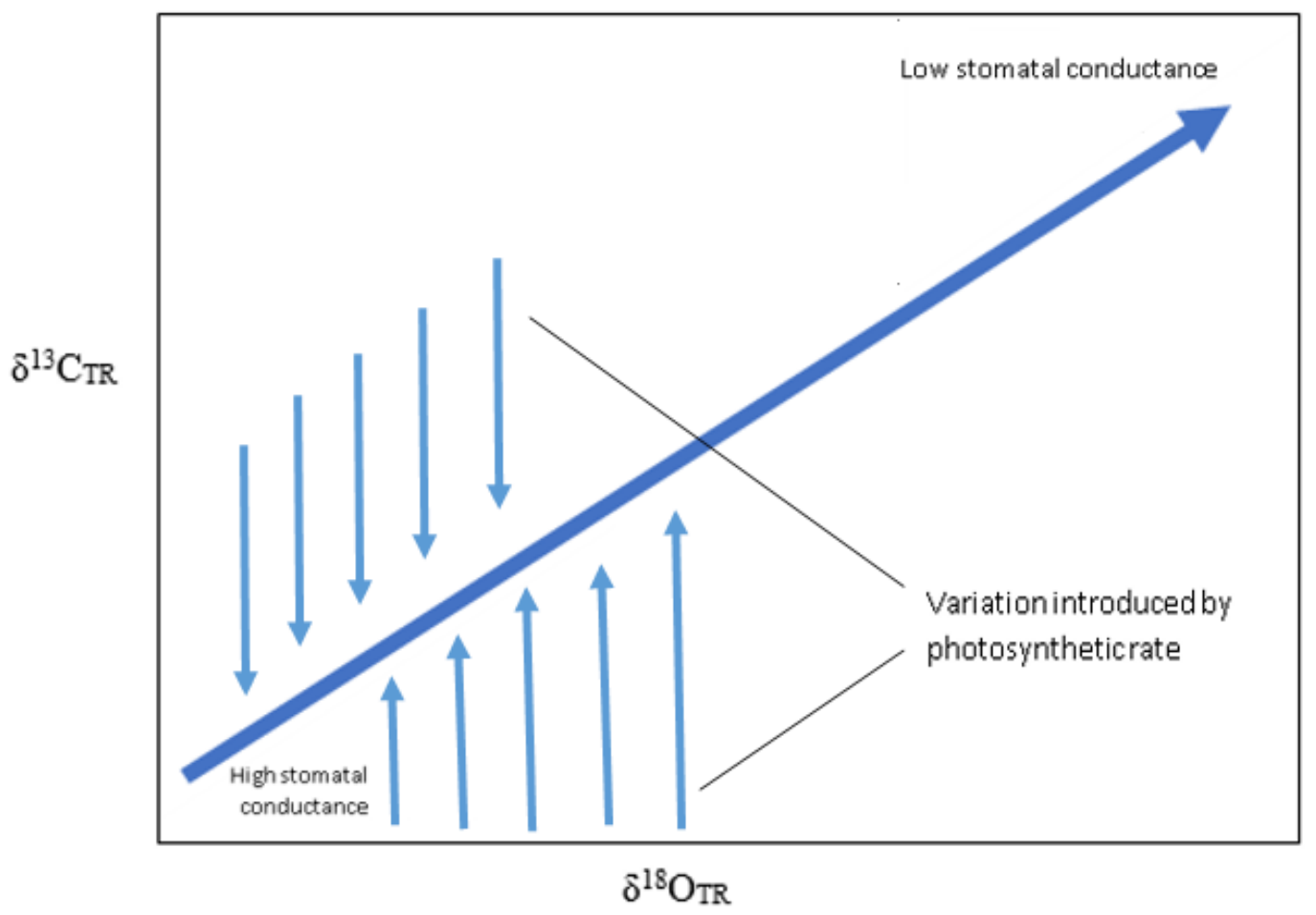

Figure 1: The expected relationship between $\delta^{18} O_{T R}$ and $\delta^{13} C_{T R}$ when stomatal conductance is a controlling factor for both isotopes.

In temperate latitudes, west coast climates experience cool temperatures and abundant moisture throughout the year, particularly in montane settings. While several records from temperate west coasts exist in the Northern Hemisphere (Hartl-Meier et al., 2015, Porter et al., 2014), there are fewer tree ring isotope studies from the Southern Hemisphere. Lavergne et al. (2016) used $\delta^{18} \mathrm{O}_{\mathrm{TR}}$ in two mid-latitude Southern Hemisphere tree species to reconstruct past temperatures. Samples of Fitzroya cupressoides and Nothofagus pumilio were collected from high-elevation sites in northern Patagonia, Argentina, at elevations of 950m - $1610 \mathrm{~m}$ above sea level. These sites receive $700-1000 \mathrm{~mm}$ of rainfall each year. For one species this team observed, $\delta^{18} \mathrm{O}_{\mathrm{TR}}$ correlated with summer (December - May) temperatures, and the relationship was statistically significant. This tree was used to reconstruct December - May mean temperatures for the time period where instrumental data were available, producing a model that predicts $35 \%$ of the variability in summer temperatures, indicating that Nothofagus pumilio has potential for paleoclimate reconstructions, and specifically SAM reconstructions (Fig. 2). 


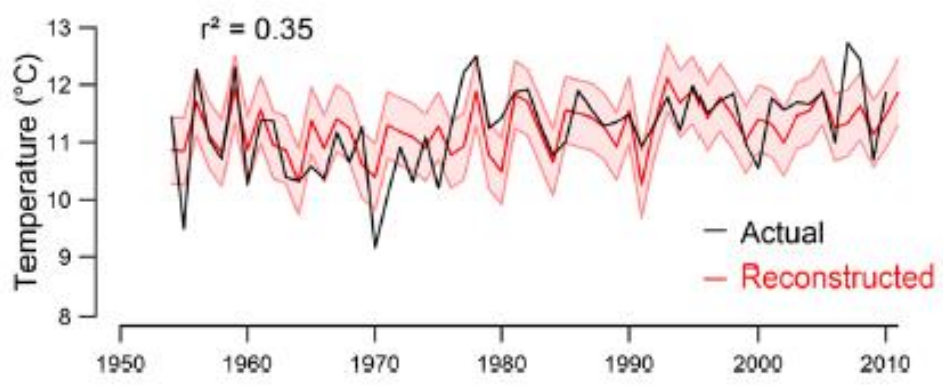

Figure 2: Reconstructed December - May mean temperatures using N. pumilo oxygen isotopes (Lavergne et al., 2016).

Given the spatial and temporal asymmetry of SAM effects on climate, it is important to recognize the conditions that could potentially be captured by tree ring proxies used to reconstruct the SAM. Tree ring records are annually resolved; however, because of the growing season of trees, the climatic signal tends to be limited to summer months (Cook et al., 1991; Allen et al., 2017). Like other tree ring records, tree-ring isotope records are annually dated, and the growing season tends to dominate the signal of whole-wood isotopic measurements (Treydte et al., 2014). Water storage from previous seasons can cause variations in the early wood that may not reflect early growing season conditions (Waring et al., 1979; Treydte et al., 2014).

Seasonal resolution records from tree ring isotopes are possible, but require careful dissection of earlywood, formed in spring, and latewood, formed in autumn. Some studies use only the latewood of tree rings to correlate with climate variables. This method can result in low-mass samples, as the latewood of trees is often smaller in width than the earlywood. Fu et al. (2017) observed earlywood and latewood trends in $\delta^{18} \mathrm{O}_{\mathrm{TR}}$ for Pinus kesiya and Pinus armandii, finding that $\delta^{18} \mathrm{O}$ of earlywood correlated with climate variables (relative humidity and precipitation) in the spring and the $\delta^{18} \mathrm{O}$ of latewood correlated with climate variables in autumn. These results suggest that earlywood/latewood separation may be of use in sites where there is high seasonal variation in climatic conditions. However, whole-ring isotope analysis may be the only option when radial growth is slow and rings are too small to separate earlywood from latewood.

While there has been a notable juvenile effect in $\delta^{13} \mathrm{C}_{\mathrm{TR}}$ for numerous trees, there have been fewer examples of juvenile effects for $\delta^{18} \mathrm{O}_{\mathrm{TR}}$ (Leavitt et al., 2010). Duffy et al. (2017) found that both carbon and oxygen isotopes in northern hemisphere oak trees exhibited very short juvenile effects, and excluding the first five rings of these trees was sufficient enough to account for the effect. While this is a different type of tree in a different part of the world, there is little other evidence to suggest a notable juvenile effect in $\delta^{18} \mathrm{O}_{\text {TR. }}$. Only one tree I measured (606) would risk having altered values due to a juvenile effect.

\section{Athrotaxis selaginoides}

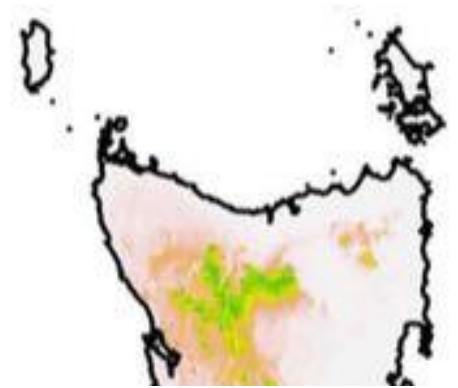

Figure 3: The range of $A$.

selaginoides, as modeled by Porfirio et al., 2014
Athrotaxis selaginoides, known by the common name "King Billy Pine", is a conifer species in the genus Athrotaxis, which is endemic to Tasmania. As a temperate rainforest species, $A$. selaginoides occurs in wet sites, at a wide range of altitudes from $\sim 400-1200 \mathrm{~m}$. The species is generally slow growing at maturity, 
only adding a few millimeters of radial growth each year. The range of A. selaginoides has been reduced due to fire over time, particularly after European settlement (Cullen, 1991), and as a result it can currently only be found in discontinuous areas across Tasmania protected from frequent fire (Fig. 3).

Though dating of trees from the Athrotaxis genus was initially uncertain (Ogden, 1978), species from this genus have considerable potential for dendrochronological studies. Allen et al. (2017) produced a millennial-length chronology for Cradle Mountain, Tasmania using ring width in $A$. selaginoides. The chronology was compared to the only other existing millennial-length chronology in Australia, that of the species Lagarostrobos franklinii on Mount Read, Tasmania. The sites for these two chronologies are within $\sim 50 \mathrm{~km}$ of each other and receive similar climate conditions. For this reason, differences between the two chronologies may be the result of either local conditions or physiological differences between the two species. The shapes of the temperature correlations (maximum, minimum, and mean for each month) for the two chronologies follow similar patterns, correlating negatively with the prior growing season but positively for the current growing season. However, correlations with temperature variables for the A. selaginoides chronology are notably weaker than those of the L. franklinii chronology. The two chronologies do not share narrow rings, supporting the idea that different factors may impact growth of the two species. The correlations with climate variables for the A. selaginoides chronology are too weak for it to be used on its own to reconstruct climate conditions. That said, a reconstruction of such a great length is immensely useful in a multi-proxy approach to reconstructing climate conditions in the Southern Hemisphere.

While ring width in the A. selaginoides population on Cradle Mountain is weakly correlated with climate variables, wood density of the rings of the Athrotaxis genus and related trees in Tasmania have paleoclimatic potential. Allen et al. (2012) correlated average wood density in the rings of two Tasmanian tree species (Athrotaxis cupressoides and Phyllocladus aspleniifolius) with temperature variables. In general, for both species, correlations between average density and temperature were opposite in sign than correlations between ring width and temperature. However, these correlations were found to be much stronger than those of ring width and temperature, exceeding $\mathrm{r}=0.5$ when correlated with maximum temperature in the summer months. O'Donnell et al. (2016) found similar results for A. cupressoides and suggested a method that uses the complimentary signals of tree ring width and mean density to reconstruct climate in Australia.

The results of these studies make it clear that the use of multiple measures and varied proxies can be used to strengthen the relatively weak ring width signals of trees in southeastern Australia. While tree-ring width and other wood properties provide a useful record of past conditions, annual ring growth is influenced by a wide variety of factors and can be heavily influenced by local conditions (McCarroll and Loader, 2004). This is evidenced in the Athrotaxis genus by relatively low temperature correlations with ring width $(\mathrm{r}=-0.2-0.4$, Allen et al., 2017) and wood properties ( $r=-0.5-0.3$, Allen et al., 2012). By contrast, the mechanisms that determine stable isotope ratios in tree rings are better understood, more consistent, and have more potential for site-to-site comparison given the standardized measurement of isotopic ratios. The combination of ring width proxies and stable isotope proxies has been used to produce improved 
reconstructions (Gagen et al., 2006). If stable isotope data is implemented into existing reconstructions of Southern Hemisphere climate, it might be possible to gain a greater understanding of the processes that control regional climate effects, such as the SAM and related systems.

\section{Methods}

\section{Study Area}

A research team conducted tree ring sampling of live $A$. selaginoides trees near the summit of Mount Read $\left(41.84^{\circ} \mathrm{S}, 145.54^{\circ} \mathrm{E}, 1123 \mathrm{~m}\right)$, located on the west coast of Tasmania, Australia during January 2020 (Fig. 4). The west coast of Tasmania is characterized by a moist climate, with cold winters and warm summers (Reid et al., 1990). Median annual rainfall on Mount Read is $3768.4 \mathrm{~mm}$ (Bureau of Meteorology), which is among the highest values in Tasmania. Rainfall peaks in winter, though monthly rainfall totals exceed $170 \mathrm{~mm}$ in all months (Fig. 5). High levels of precipitation will strengthen the relationship between $\delta^{18} \mathrm{O}$ of precipitation and $\delta^{18} \mathrm{O}$ of soil water by limiting the fractionation effects of evaporation (Treydte et al. 2014). Mount Read has a peak elevation of 1123 meters, placing it at the edge of $A$. selaginoides' altitude range. The forest at the site is classified as a cool temperate rainforest and composed mainly of Athrotaxis selaginoides, Athrotaxis cuppressoides, and Lagarostrobos franklinii. The sampling site is located on a steep slope (20 - 40 degrees) near the summit of Mount Read.

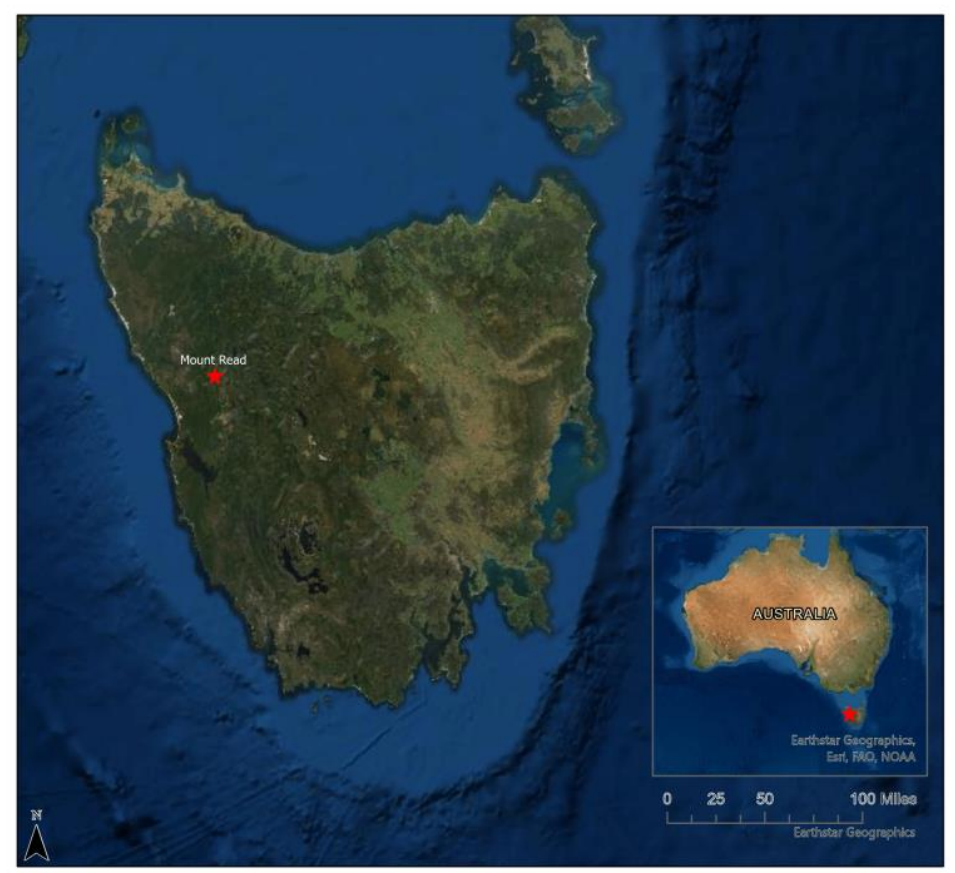

Figure 4: Map of Tasmania that highlights the study site, Mount Read (red star). 


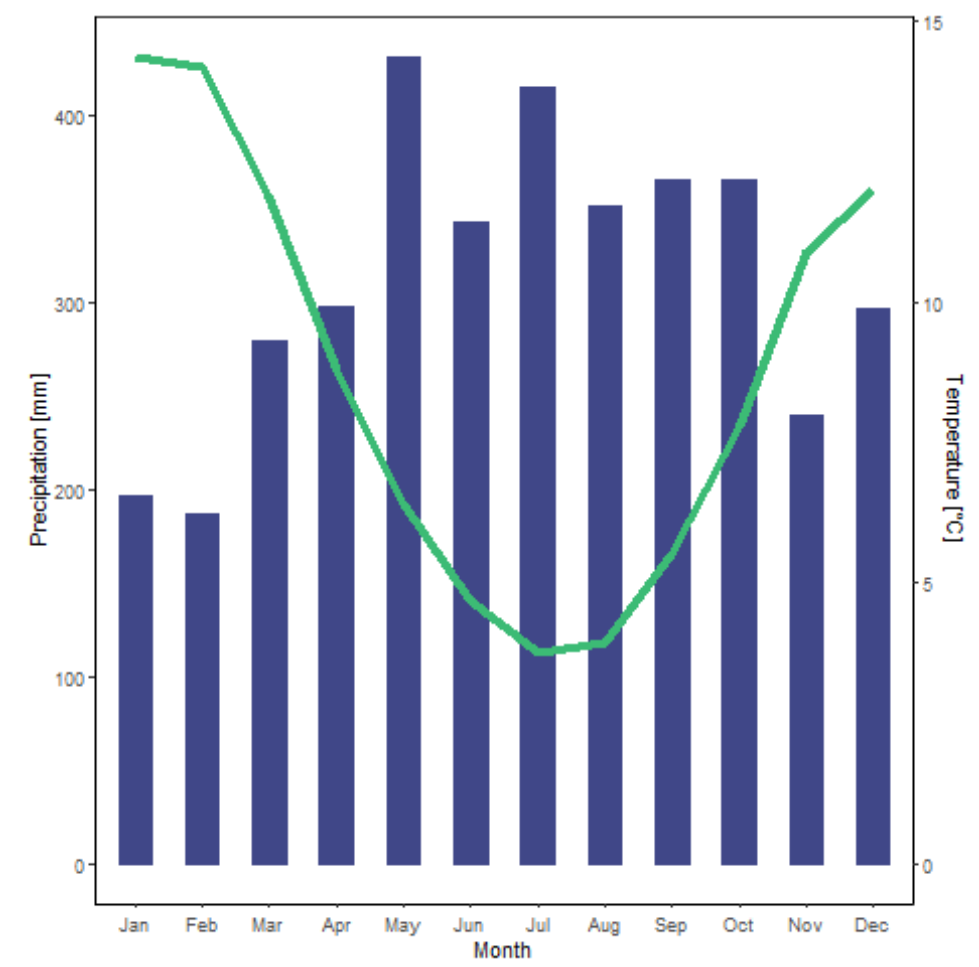

Figure 5: Climograph of Mount Read. Precipitation is the blue bars, temperature is the green line.

\section{Field methods}

A research team collected $5 \mathrm{~mm}$ cores from 20 A. selaginoides trees on Mount Read. Three cores were collected from each tree to ensure that enough mass was present to perform isotope analysis. We recorded tree height and diameter at breast height (DBH), soil depth, canopy cover, and slope at the site of each tree we sampled.

\section{Lab methods}

I mounted, sanded, dated, and measured all the cores gathered for each tree using standard dendrochronological methods (Stokes \& Smiley, 1968). For Southern Hemisphere tree ring samples, the "current" year includes the subsequent year's growing season months. Therefore, a sample assigned the year 1960 represents the growing season of September 1960 - February 1961. I measured individual ring widths and tested the accuracy of these measurements and their dating by comparing them to measurement patterns in an existing cross-dated chronology from Mount Read (Allen et al., 2017) using the crossdating software COFECHA (Holmes, 1983). The existing chronology covers the period $439 \mathrm{BCE}-2018 \mathrm{CE}$ and contains 147 ring width series. For the purposes of comparing stable isotope proxies developed here with one derived from ring width series, I created a detrended tree ring width chronology, including the new series collected and measured in this study. I power transformed (Cook and Peters, 1997) and detrended the increment series using an age-dependent smoothing spline where the frequency response is set at 0.50 at a wavelength of 0.67 (2/3 length of each series). Residual values from the detrended series were combined in a mean-value chronology using Tukey's biweight robust mean. For 
subsequent analysis, I used the years 1960 - 2018 of the chronology, with a sample depth of 55 ring width series.

For isotope analysis, I selected sampled trees with at least two cores that dated reliably (correlation with the master chronology $>0.3$ ). For each core with reliable dating, I used a rotary microtome to section individual rings for the years 1959 - 2019. The microtome was used to slice the tree rings into shavings $20 \mu \mathrm{m}$ thick for effective cellulose extraction. I stored shavings in polypropylene microcentrifuge tubes labeled with the correct year and tree ID. Rings that belong to the same tree were pooled by year to ensure enough mass is present to gather isotopic ratios. For example, if there are two cores for tree 605, and both of those cores have a ring that represents 2005, then those two rings were pooled together to become sample 605-2005.

Trees produce waxes, resins and lignins that are mobile in the tree and can alter the isotopic ratios in samples. To isolate only the $\alpha$-cellulose present in the wood, I used the Brendel et al. (2000) system for cellulose extraction from the whole-wood samples, ideal for both $\delta^{13} C_{\mathrm{TR}}$ and $\delta^{18} \mathrm{O}_{\mathrm{TR}}$ measurement. This method allows for batch sampling for efficiency and is designed for small-mass samples. In addition, this process does not require transferring samples between tubes, which helps to prevent sample loss. The process of cellulose extraction involves exposing each sample to acetic acid and nitric acid to isolate the cellulose from lignins and non-cellulosic polysaccharides. Then, the samples undergo four chemical washes to remove these noncellulosic compounds. The samples are dried in an oven and desiccated after this process. Prior to isotope analysis, I placed $0.20 \mathrm{mg}(+/-0.02 \mathrm{mg})$ of each dried sample into a silver capsule. I did not prepare samples for isotope analysis if they contained an insufficient mass of cellulose.

The cellulose samples were analyzed in a Costech-IRMS for $\delta^{13} C_{T R}$ and $\delta^{18} \mathrm{O}$. This is achieved through high-temperature pyrolysis, which converts the carbon and oxygen from the samples into carbon monoxide (CO). The combusted gas passes through an acid water trap that removes $\mathrm{CO}_{2}$ and $\mathrm{H} 2 \mathrm{O}$, leaving only the $\mathrm{CO}$ to be transferred to the IRMS for analysis. The combusted $\mathrm{CO}$ contains molecules of three separate species: ${ }^{12} \mathrm{C}^{16} \mathrm{O},{ }^{13} \mathrm{C}^{16} \mathrm{O}$, and ${ }^{12} \mathrm{C}^{18} \mathrm{O}$. species correspond to mass numbers 28,29 , and 30 . The IRMS tracks the masses of $\mathrm{CO}$, which allows the user to determine stable isotope ratios based on the proportion of the $\mathrm{CO}$ molecules measured for each of these masses.

A 99-slot autosampler was used for processing the cellulose samples. For each run, 72 cellulose samples were analyzed along with 27 samples of standards. The samples were measured against two standards, SAC (Sigma alpha cellulose) and AKC (Alaskan corn). Drift in the samples was calculated based on drift in the measurements of the reference gases.

The samples were left in the autosampler overnight sealed with helium gas to dehydrate them. The autosampler was attached to a Costech HTG 02 elemental analyzer. The Costech EA combusted the samples at 1080 degrees $\mathrm{C}$ in a reactor so that the carbon and oxygen in the samples became CO. This reactor consists of a quartz tube containing quartz wool, nickel wool and glassy carbon. The $\mathrm{CO}$ was then routed through an acid water trap made of quartz wool, magnesium perchlorate, and a $\mathrm{CO}_{2}$ absorbent. This trap absorbed $\mathrm{CO}_{2}$ and excess water. The $\mathrm{CO}$ was then routed into the gas chromatography oven (75 degrees $\mathrm{C}$ ) which separated compounds to be measured. From here, the gases were routed to the mass spectrometer which detected and 
measured the types of $\mathrm{CO}$ present - 28, 29, and 30 which indicates different types of $\mathrm{CO}$. This entire process was performed under helium flow to route the $\mathrm{CO}$ through the mechanism and avoid exposure to outside air. Helium is an inert gas, making it an ideal carrier gas. The helium was sent routed through the elemental analyzer at a pressure of 9.5 psi to provide a flow rate of roughly $110 \mathrm{~mL} / \mathrm{minute}$.

We recorded all $\delta^{18} \mathrm{O}_{\mathrm{TR}}$ samples as the proportion of ${ }^{18} \mathrm{O} /{ }^{16} \mathrm{O}$ using per mil (\%o) notation with respect to Vienna Standard Mean Ocean Water (VSMOW).

\section{Analysis}

A. Checked and cleaned $\delta^{18} \mathrm{O}_{\mathrm{TR}} \& \delta^{13} \mathrm{C}_{\mathrm{TR}}$ data

I performed Suess corrections on the $\delta^{13} \mathrm{C}_{\mathrm{TR}}$ dataset to remove the long-term positive trend in the $\delta^{13} \mathrm{C}_{\mathrm{TR}}$ data resulting from the addition of fossil-fuel derived $\mathrm{CO}_{2}$ to the atmosphere, which is depleted in $\delta^{13} \mathrm{C}$ (Keeling, 1979). I used atmospheric $\delta^{13} \mathrm{C}$ measurements (Graven et al., 2017, Table 2) and flask measurements from Baring Head, New Zealand (Keeling et al., 2001) to correct $\delta^{13} \mathrm{C}_{\mathrm{TR}}$ data. The Baring Head measurements are latitudinally similar to Mount Read $\left(41.4^{\circ} \mathrm{S}\right.$ vs. $\left.41.8^{\circ} \mathrm{S}\right)$, so I performed a latitude adjustment on the Graven measurements for the period 1960 - 1984. Therefore, the final dataset that I used for Suess corrections consisted of latitude-adjusted Graven measurements for 1960 - 1984 and Baring Head flask measurements for $1985-2018$.

Table 2: A list of data I used in this research with references and source links.

\begin{tabular}{|c|c|c|c|c|c|c|}
\hline Dataset & $\begin{array}{l}\text { Period } \\
\text { Available }\end{array}$ & $\begin{array}{l}\text { Period } \\
\text { Used }\end{array}$ & Resolution & Variables & References & Access \\
\hline GNIP & $1979-2002$ & $\begin{array}{l}1979- \\
2002\end{array}$ & Monthly & $\delta^{18} \mathrm{O}_{\mathrm{P}}$ & $\begin{array}{l}\text { IAEA/WMO, } \\
2021\end{array}$ & https://www.iaea.org/services/networks/gnip \\
\hline \multirow[t]{7}{*}{ SILO } & \multirow[t]{7}{*}{$1889-2021$} & \multirow{7}{*}{$\begin{array}{l}1959- \\
2019\end{array}$} & \multirow[t]{7}{*}{ Monthly } & Rainfall & \multirow{7}{*}{$\begin{array}{l}\text { Jeffrey et al., } \\
2000\end{array}$} & \multirow[t]{7}{*}{ https://www.longpaddock.qld.gov.au/silo/gridded-data/ } \\
\hline & & & & Radiation & & \\
\hline & & & & Temperature & & \\
\hline & & & & RH & & \\
\hline & & & & VPD & & \\
\hline & & & & PET & & \\
\hline & & & & RH & & \\
\hline \multirow[t]{3}{*}{$\begin{array}{l}\text { MRD } \\
\text { Stations }\end{array}$} & $1990-2021$ & $\begin{array}{l}1990- \\
2021\end{array}$ & Monthly & $\begin{array}{l}\text { Solar } \\
\text { Radiation }\end{array}$ & \multirow[t]{3}{*}{$\begin{array}{l}\text { Bureau of } \\
\text { Meteorology }\end{array}$} & \multirow[t]{3}{*}{ http://www.bom.gov.au/climate/averages/tables/cw_097085.shtml } \\
\hline & $1996-2021$ & $\begin{array}{l}1996- \\
2021\end{array}$ & Monthly & Temperature & & \\
\hline & $1997-2021$ & $\begin{array}{l}1997- \\
2021\end{array}$ & Monthly & Precipitation & & \\
\hline Carbon & $1850-2015$ & $\begin{array}{l}1960- \\
2015\end{array}$ & Annual & Global $\delta^{13} \mathrm{CO}_{2}$ & $\begin{array}{l}\text { Graven et al., } \\
2017\end{array}$ & https://doi.org/10.5194/gmd-10-4405-2017-supplement \\
\hline Baring Head & $1985-2021$ & $\begin{array}{l}1985- \\
2018\end{array}$ & Monthly & $\begin{array}{l}\delta^{13} \mathrm{C} \text { Flask } \\
\text { Measurements }\end{array}$ & $\begin{array}{l}\text { Keeling et al., } \\
2001\end{array}$ & https://scrippsco2.ucsd.edu/data/atmospheric_co2/nzd.html \\
\hline
\end{tabular}




\begin{tabular}{|c|c|c|c|c|c|c|}
\hline $\begin{array}{l}\text { Marshall } \\
\text { SAM Index }\end{array}$ & $1957-2021$ & $\begin{array}{l}1960- \\
2018\end{array}$ & Monthly & SAM Index & $\begin{array}{l}\text { Marshall } \\
(2003)\end{array}$ & https://legacy.bas.ac.uk/met/gima/sam.html \\
\hline \multirow[t]{2}{*}{ ERA5 } & \multirow[t]{2}{*}{$1950-2021$} & \multirow{2}{*}{$\begin{array}{l}1959- \\
2019\end{array}$} & \multirow[t]{2}{*}{ Monthly } & Temperature & \multirow{2}{*}{$\begin{array}{l}\text { Hersbach et } \\
\text { al., } 2019 \text {; } \\
\text { Bell et al., } \\
2020\end{array}$} & \multirow{2}{*}{$\begin{array}{l}\text { https://cds.climate.copernicus.eu/cdsapp\#!/dataset/reanalysis- } \\
\text { era5-single-levels-monthly-means-preliminary-back- } \\
\text { extension?tab=overview }\end{array}$} \\
\hline & & & & Precipitation & & \\
\hline $\begin{array}{l}\text { NCEP/NCAR } \\
\text { Reanalysis }\end{array}$ & $1948-2021$ & $\begin{array}{l}1960- \\
2019\end{array}$ & 6-hour & $\begin{array}{l}\text { Atmospheric } \\
\text { Pressure }\end{array}$ & NCEP/NCAR & https://psl.noaa.gov/data/gridded/data.ncep.reanalysis.html \\
\hline
\end{tabular}

From here, I used median values at each year to create a single time series of both $\delta^{18} \mathrm{O}_{\mathrm{TR}}$ and $\delta^{13} \mathrm{C}_{\mathrm{TR}}$. I chose to use median instead of mean in order to reduce the influence of outliers. I calculated bootstrapped $95 \%$ confidence intervals of the median value at each year to provide a measure of variability.

B. $\delta^{18} \mathrm{O}_{\mathrm{TR}}$ VS. $\delta^{18} \mathrm{O}_{\mathrm{P}}$

If $\delta^{18} \mathrm{O}_{\mathrm{P}}$ is strongly correlated with $\delta^{18} \mathrm{O}_{\mathrm{TR}}$, then variation in $\delta^{18} \mathrm{O}_{\mathrm{TR}}$ is likely influenced by source region effects/conditions. However, if there is no relationship or a very weak relationship, then local conditions may be a stronger influence on $\delta^{18} \mathrm{O}_{\mathrm{TR}}$. I used IAEA Global Network of Isotopes in Precipitation (GNIP) measurements of $\delta^{18} \mathrm{O}_{\mathrm{P}}$ at Cape Grim, Tasmania (1979 - 2002) to assess the relationship between $\delta^{18} \mathrm{O}_{\mathrm{TR}}$ and $\delta^{18} \mathrm{OP}_{\mathrm{P}}$ I performed Pearson correlations between $\delta^{18} \mathrm{O}_{\mathrm{TR}}$ and monthly measurements of $\delta^{18}$ Op from GNIP for September through February.

C. Assess local site influences

To assess local climate influences on $\delta^{18} \mathrm{O}_{\mathrm{TR}}$, I calculated correlations between my $\delta^{18} \mathrm{O}_{\mathrm{TR}}$ values and local climate conditions on Mount Read. I obtained rasterized climate data (precipitation, minimum and maximum temperature, relative humidity, vapor pressure deficit, solar radiation) from the Australian Bureau of Meteorology's SILO database (Jeffrey et al., 2001), recorded as daily values in netcdf format at $0.05 \times 0.05$-degree resolution (1889 - present). SILO spatial grids are produced by interpolation of data from climate stations across Australia. I created monthly averages (with the exception of precipitation, which is monthly totals) based on these daily grids. I extracted values for Mount Read from monthly SILO grids via bilinear interpolation of the four closest cells to my study site (145.54, -41.84). I performed correlations between these SILO data points and Mount Read station data (Bureau of Meteorology) for the period where station data are available to verify that the SILO measurements closely reflect the values found at the Mount Read station (Fig. 6). 

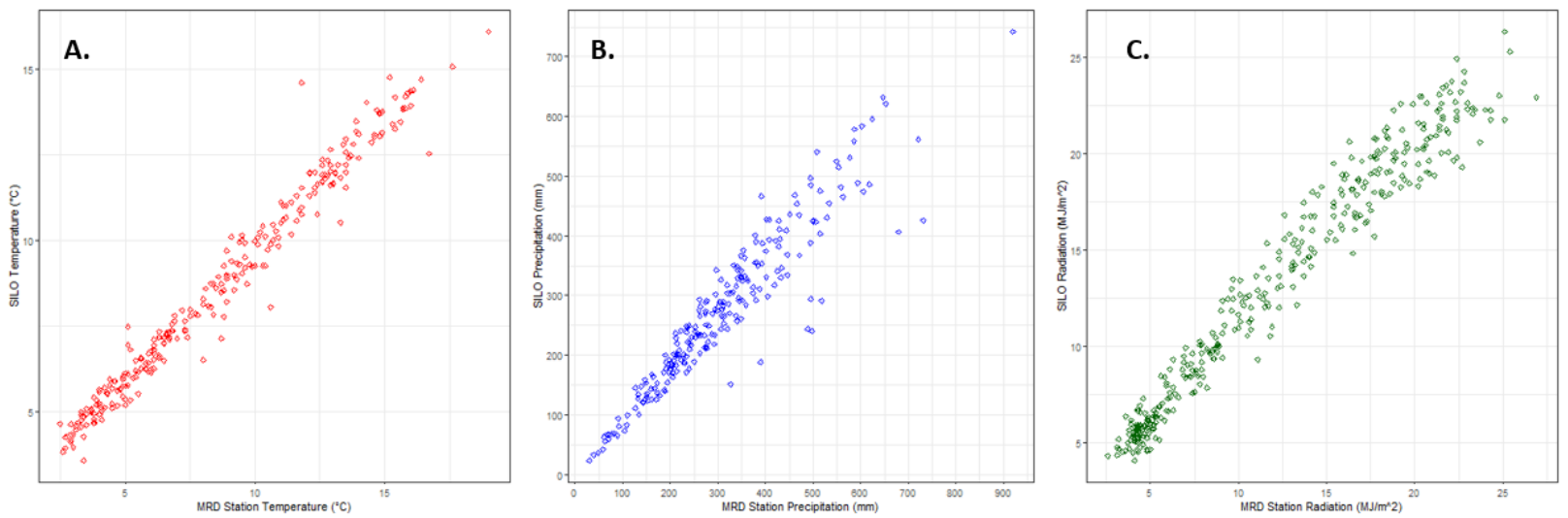

Figure 6: Comparisons between Mount Read station measurements and interpolated SILO values at Mount Read for temperature $(A)$, precipitation $(B)$, and solar radiation $(C)$.

Based on known relationships between oxygen isotopes and climate conditions (Table 1), I would expect a positive relationship between $\delta^{18} \mathrm{O}_{\mathrm{TR}}$ and local temperature, and a negative relationship between $\delta^{18} \mathrm{O}_{\mathrm{TR}}$ and local moisture. I calculated correlations between the Mount $\operatorname{Read} \delta^{18} \mathrm{O}_{\mathrm{TR}}$ and 3-month rolling averages of temperature, precipitation, vapor pressure deficit (VPD), relative humidity, and solar radiation at Mount Read for September through February. The seasonal correlations allowed me to determine if certain seasons influence the $\delta^{18} \mathrm{O}_{\mathrm{TR}}$ record in these tree rings stronger than others, thus those seasons could be well represented in any climate proxy produced by the tree ring isotopes.

I also calculated correlations with 3-month rolling averages of local climate for $\delta^{13} \mathrm{C}_{\mathrm{TR}}$. Carbon isotopes can provide information about stomatal conductance and photosynthetic rate, and knowing if relationships between these factors and $\delta^{13} \mathrm{C}_{\mathrm{TR}}$ are present can help with interpretation of $\delta^{18} \mathrm{O}_{\mathrm{TR}}$. For comparison, I also calculated Pearson correlations between ring width and 3-month rolling averages of local climate, as above.

To further test the influence of local moisture conditions on the isotopic values, I performed a dual isotope comparison. If there is a positive relationship between $\delta^{18} \mathrm{O}_{\mathrm{TR}}$ and $\delta^{13} \mathrm{C}_{\mathrm{TR}}$, then it is likely that local moisture is influential in determining the values found in both isotope series. I calculated a Pearson correlation between median $\delta^{18} \mathrm{O}_{\mathrm{TR}}$ and $\delta^{13} \mathrm{C}_{\mathrm{TR}}$. If local moisture conditions influence both $\delta^{18} \mathrm{O}_{\mathrm{TR}}$ and $\delta^{13} \mathrm{C}_{\mathrm{TR}}$, I would expect a relationship similar to the plot pictured in Figure 1. I would also expect strong correlations between the isotopic values and relative humidity, precipitation, and VPD.

\section{Source Region}

$\delta^{18} \mathrm{OP}_{\mathrm{P}}$ at Mount Read is not only dependent upon local climate conditions, but also the conditions at the source region of precipitation. To understand the potential source region of precipitation for Mount Read, I calculated backward trajectories for Mount Read, Tasmania using the model HYSPLIT (Stein et al., 2015), which is accessible in the R environment through the package SplitR (Iannone, 2016). Using NCEP/NCAR reanalysis data as atmospheric pressure inputs, I simulated trajectories at $10 \mathrm{~m}$ elevation for the period September - February. I computed five-day backwards trajectories every six hours at 5-day intervals over this season. I then summarized 
these trajectories by calculating the frequency of trajectories crossing 0.5 -degree cells during the period of record.

The SAM may be a factor that changes moisture delivery paths to Tasmania. Therefore, the SAM may be a factor that influences $\delta^{18} \mathrm{O}_{\mathrm{TR}}$, as this implies a change in source region with changing SAM. I used HYSPLIT backward trajectories to determine if there was any difference in moisture delivery between SAM-positive states and SAM-negative states. Using the Marshall SAM index (Marshall, 2003) I composited backward trajectories at Mount Read during the 10 years where the spring and summer (September - February) were the most SAM-positive as well as the 10 years where spring and summer were most SAM-negative. I then calculated anomalies (from the mean conditions calculated above) to determine how the source regions differ from the mean conditions during SAM-positive and SAM-negative years. I also calculated anomalies for the top $25 \%$ and bottom $25 \%$ of years by median $\delta^{18} \mathrm{O}_{\mathrm{TR}}$ and September - February average $\delta^{18} \mathrm{O}_{\mathrm{P}}$ (measured by GNIP) to assess moisture delivery patterns associated with variation in these datasets.

To observe which regional climate variables influence the $\delta^{18} \mathrm{O}_{\mathrm{TR}}$ series, as well as the specific areas where they are influential, I created spatial correlation maps between the $\delta^{18} \mathrm{O}_{\mathrm{TR}}$ series and regional climate variables. I performed Pearson correlations between the $\delta^{18} \mathrm{O}_{\mathrm{TR}}$ series and spatial climate fields from ECMWF ERA5 to assess any relationship with source region conditions. ERA5 combines a physics-based model output with observational data to produce a global field of countless climate variables (Hersbach et al., 2019). The ERA5 dataset spans from 1950 to the present, and it is updated daily with hourly measurements. Monthly means have been pre-calculated by the ECMWF, which I used in my analyses. I used total precipitation and temperature at $2 \mathrm{~m}$ elevation for the years 1960 - 2018. For each variable, I extracted ERA5 spatial fields to an extent that includes the source region of precipitation to Mount Read as defined by the mean HYSPLIT analysis above. Then, for each cell, I correlated the climate fields with the $\delta^{18} \mathrm{O}_{\text {TR }}$ series. I compared these spatial correlation maps to the HYSPLIT-produced back trajectory summary to validate that the most influential areas are the source of precipitation over Mount Read. In addition, due to the monthly resolution of these data, I observed if source region influence is stronger in certain seasons. I compared the influence of source region conditions with the influence of local conditions, providing more insight into what climate information is reflected in the $\delta^{18} \mathrm{O}_{\mathrm{TR}}$ series. I also calculated spatial correlations between ERA5 climate data with average GNIP $\delta^{18} \mathrm{O}_{\mathrm{P}}$ for September - February for the years $1979-2002$. I performed this analysis to assess differences in moisture delivery that result in variations in $\delta^{18} \mathrm{OP}_{\mathrm{P}}$.

\section{Results}
A. $\delta^{18} \mathrm{O}_{\mathrm{TR}}$

I sectioned 20 cores from 10 trees into individual years using the microtome producing a total of 521 cellulose samples for isotope analysis. In the $\delta^{18} \mathrm{O}_{\mathrm{TR}}$ series, not every year is represented by 
all 10 trees, though every year is represented by at least 8 trees (mean sample size per year $=$ 8.75 trees) thus exceeding the typical minimum sample depth of 4-6 cores per tree (Leavitt, 2010).

The $\delta^{18} \mathrm{O}_{\text {TR }}$ values of the $A$. selaginoides trees have a low EPS $(0.566)$ and rbar $(0.13)$ for the period 1960 - 2018 (Table 3) relative to that of the ring width series EPS (0.965) and rbar (0.222). The series has a low Gleichläufigkeit (GLK) value (0.555), otherwise known as the sign test, which is a measure of synchronicity between trees. The series shows weak, yet significant first-order and second-order autocorrelation $(\mathrm{AC} 1=0.319 ; \mathrm{AC} 2=0.273)$. The mean of the $A$. selaginoides $\delta^{18} \mathrm{O}_{\mathrm{TR}}$ chronology for all years is $27.72 \%$ ( $\mathrm{sd}=0.87 \%$ ). The means for individual trees range from $26.83 \%$ to $28.28 \%$. Variability between trees is greater from $1960-1995$ (sd $=0.97 \%$ ) than from $1996-2018(\mathrm{sd}=0.71 \%$ ) (Fig. 7A). Variability does appear to tighten from $\sim 1980-1987$, before widening again from $\sim 1988-1995$. No trend was found in the data. Mean $\delta^{18} \mathrm{O}_{\mathrm{TR}}$ and $\delta^{18} \mathrm{O}_{\mathrm{TR}}$ standard deviation are not correlated to any site conditions (Appendix 1).

Table 3: Comparison between $\delta^{18} O_{T R}$ and the A. selaginoides ring width chronology, including the number of series, rbar (average interseries correlation), EPS (expressed population signal), SNR (signal to noise ratio), and GLK (Gleichläufigkeit sign test) for the period of instrumental record (1960-2018).

\begin{tabular}{|c|c|c|c|c|c|}
\hline Tree Ring Series & Series (n) & Rbar & EPS & SNR & GLK \\
\hline$\delta^{18} \mathrm{O}_{\mathrm{TR}}$ & 10 & 0.13 & 0.566 & 1.302 & 0.555 \\
\hline$\delta^{13} \mathrm{C}_{\mathrm{TR}}$ & 9 & 0.318 & 0.791 & 3.787 & 0.592 \\
\hline KBP Ring Width & 55 & 0.222 & 0.965 & 27.328 & 0.637 \\
\hline
\end{tabular}

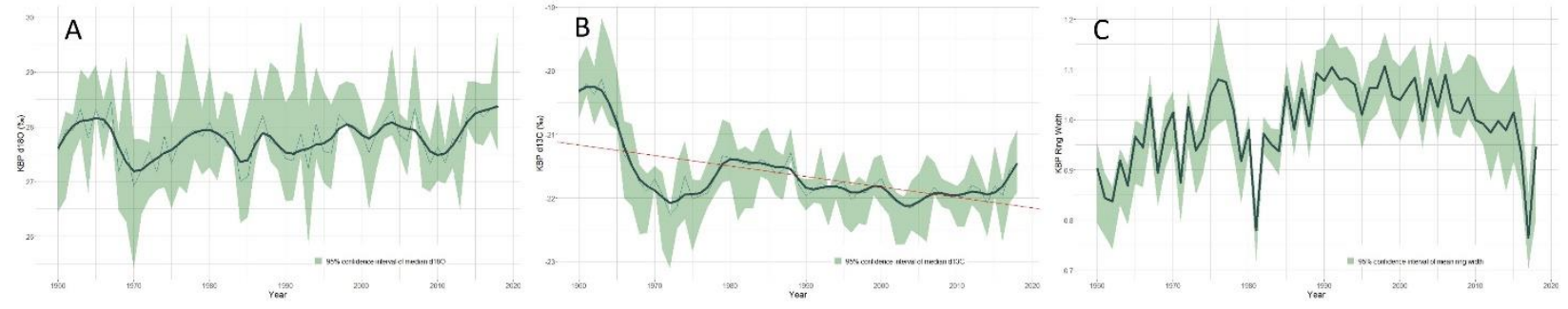

Figure 7: Representations of King Billy Pine series of $\delta^{18} O_{T R}(A), \delta^{13} C_{T R}(B)$, and ring width (C) for 1960 - 2018. Dark grey line is a spline calculated using a frequency response of 0.9 and a wavelength of 10 years of median $\delta^{18} O_{T R}$ in $(A)$ and median $\delta^{13} C_{T R}$ in (B). In (C), dark grey line is a 2/3 smoothing spline of mean ring width. Light green represents a 95\% confidence interval in all plots. Light blue line in $(A)$ and $(B)$ is actual median $\delta^{18} O_{T R}$ and $\delta^{13} C_{T R}$ respectively. Red line in $(B)$ represents a regression line of $\delta^{13} C_{T R}$ over time ( $R$-squared $=0.333, p<0.01$ ).

The $\delta^{18} \mathrm{O}_{\mathrm{TR}}$ chronology shows a positive relationship with temperature in the late spring and early summer (Fig. 8A). The correlations with October-December temperature are significant ( $\mathrm{r}$ $=0.27, \mathrm{p}<0.05$ ), with other portions of the early growing season showing slight positive relationships as well. In addition, the correlation with January-March precipitation is significant, showing a positive relationship for the late growing season and post-season period. There is no 
significant correlation between $\delta^{18} \mathrm{O}_{\mathrm{TR}}$ and relative humidity. VPD has a positive correlation in the early growing season $(r=0.32, \mathrm{p}<0.05$ for $\mathrm{OND})$.

A. selaginoides ring width is positively correlated with irradiance in the September - November season (Fig. 8; $\mathrm{r}=0.34, \mathrm{p}<0.05$ ). All other correlations between A. selaginoides ring width and climate variables are insignificant.

A.

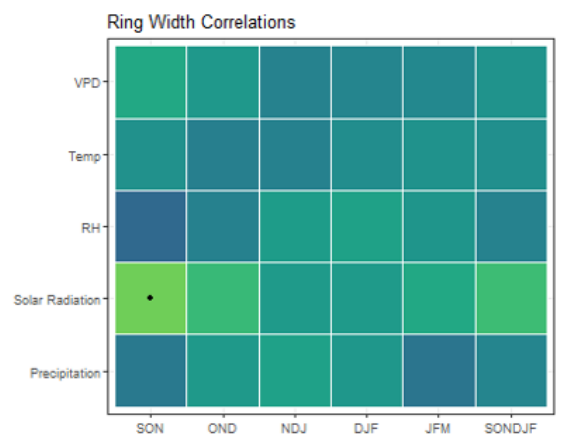

B.

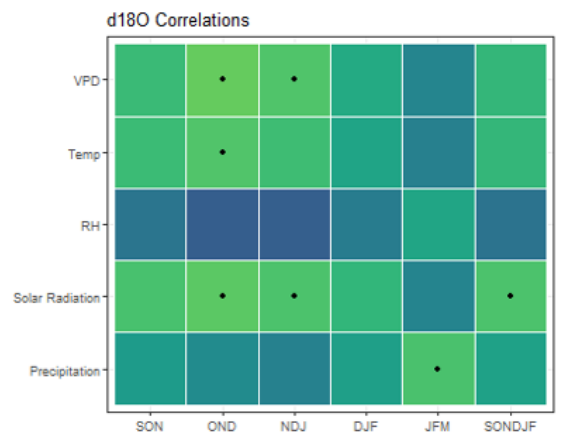

C.

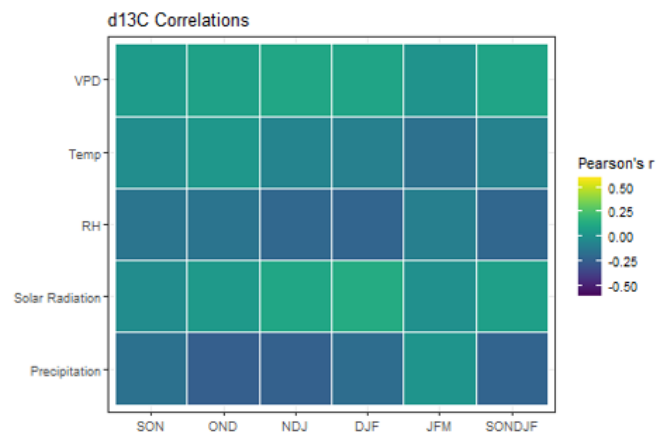

Figure 8: Correlations between ring width $(A), \delta^{18} O_{T R}(B)$, and $\delta^{13} C_{T R}(C)$ with 3-month averages of climate variables at Mount Read. Dots indicate statistically significant correlations $(p<0.05)$.

The only significant Pearson correlation between $\delta^{18} \mathrm{O}_{\mathrm{TR}}$ and $\delta^{18} \mathrm{O}_{\mathrm{P}}$ occurs in the 3 -month period of November - January (Fig. 9, $r=0.55, p<0.05$ ). This suggests that there is a strong connection between $\delta^{18} \mathrm{O}_{\mathrm{P}}$ and $\delta^{18} \mathrm{O}_{\mathrm{TR}}$ during the growing season. Correlations with GNIP for all other seasons are insignificant. 


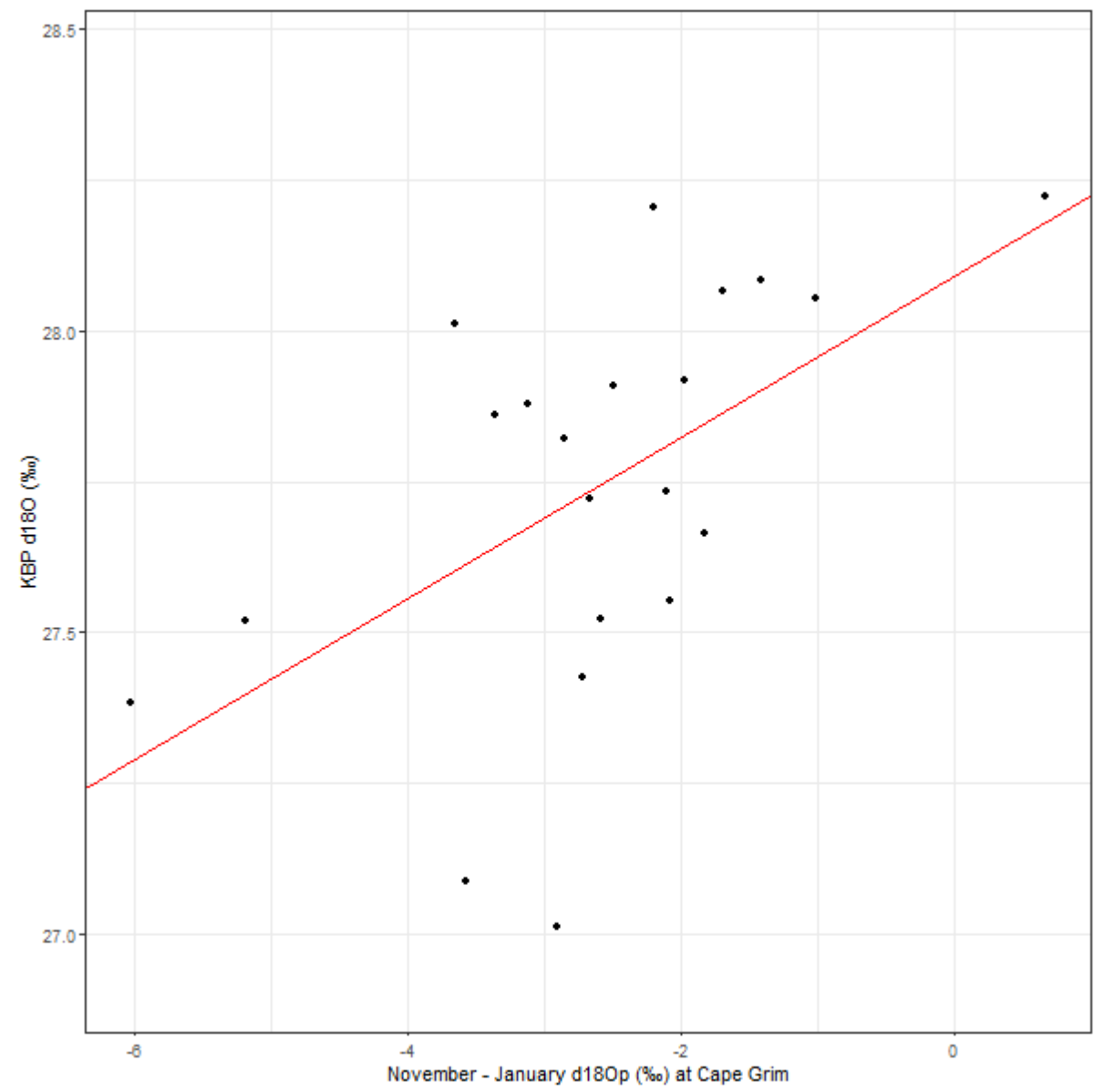

Figure 9: $\delta^{18} O_{T R}$ plotted against November - January average of $\delta^{18} O_{P}$ at Cape Grim, Tasmania. Red line represents a regression between NDJ $\delta^{18} O_{P}$ measured by GNIP and $\delta^{18} O_{T R}(R$-squared $=0.304, p=0.01)$.

Standard deviation in the $\delta^{18} \mathrm{O}_{\text {TR }}$ chronology is negatively correlated with VPD in October December and November - January; temperature in November - January and December February; solar radiation in October - December and November - January; and precipitation in September - November and January - March (Fig. 10). Both temperature and solar radiation exhibit negative correlations for September - February. 


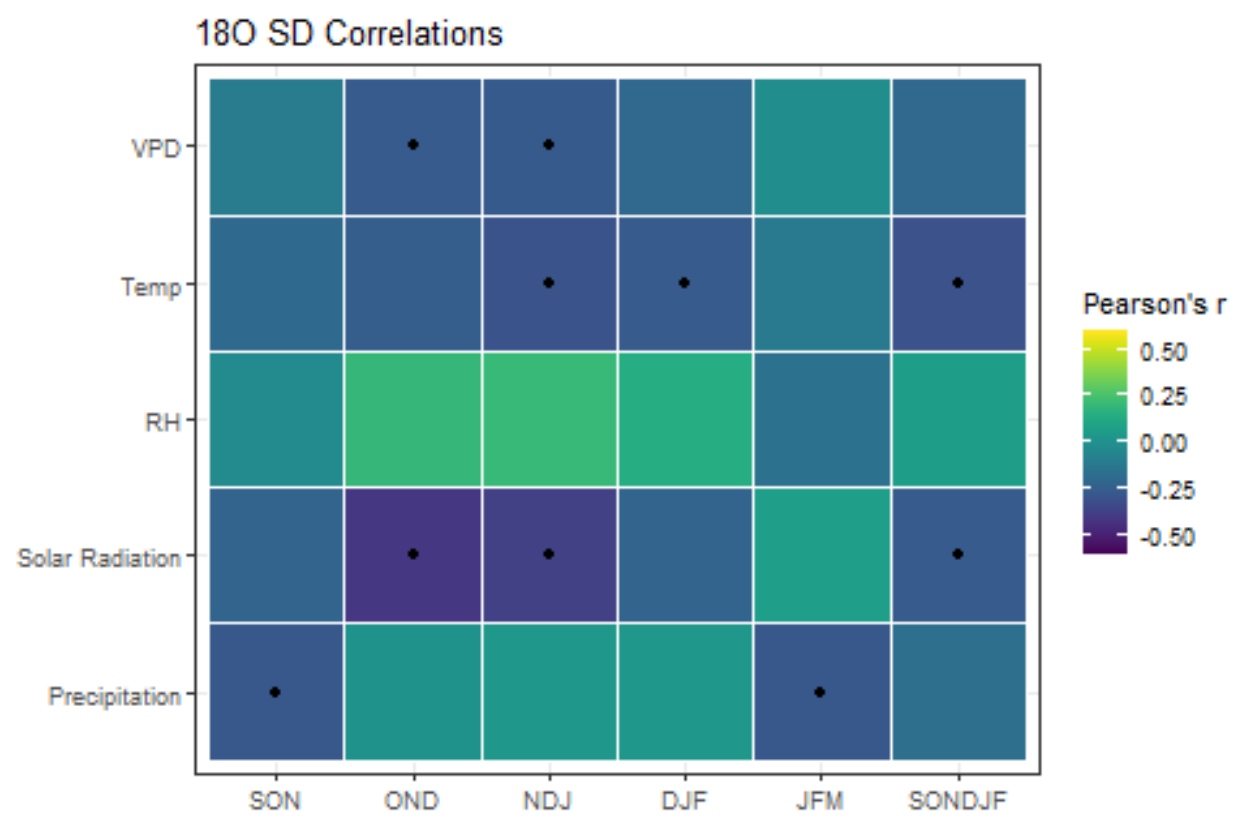

Figure 10: Correlation between annual standard deviation in $\delta^{18} \mathrm{O}_{T R}$ and 3-month rolling averages of SILO climate measures at Mount Read. Dots represent significant correlations $(p<0.05)$.

B. $\delta^{13} \mathrm{C}_{\mathrm{TR}}$

We used nine trees to produce the $\delta^{13} \mathrm{C}_{\mathrm{TR}}$ series. I removed one tree (606) which was used in the $\delta^{18} \mathrm{O}_{\mathrm{TR}}$ series to account for juvenile effects. Rbar for $\delta^{13} \mathrm{C}_{\mathrm{TR}}$ is 0.318 , indicating that the series are more highly correlated than the $\delta^{18} \mathrm{O}_{\mathrm{TR}}$ series. The mean of the A. selaginoides $\delta^{13} \mathrm{C}_{\mathrm{TR}}$ chronology for all years is $-21.64 \%$ o $(\mathrm{sd}=0.49 \%$ ). The means for individual trees range from $22.08 \%$ o to $-21.24 \%$. There is a distinctive decline in $\delta^{13} \mathrm{C}_{\mathrm{TR}}$ after $\sim 1965$ (Fig. 7B). Variability is relatively low throughout the chronology. The negative trend shown by the linear model in Figure 12 is significant, though it appears to mainly be driven by the enriched values before 1965.

Monthly correlations between $\delta^{13} \mathrm{C}_{\mathrm{TR}}$ and local climate variables show no significant relationships (Fig. 8B). Most correlations are near 0, indicating that no individual signal can be gathered from the $\delta^{13} \mathrm{C}_{\mathrm{TR}}$ series.

\section{Dual Isotopes}

There is not a strong relationship between $\delta^{18} \mathrm{O}_{\mathrm{TR}}$ and $\delta^{13} \mathrm{C}_{\mathrm{TR}}$, and their correlation is not significant (Fig. 11). The relationship seen in Figure 11 is unlike the one modeled in Figure 1. This aligns with the low correlations between both isotope measures and local moisture variables. 


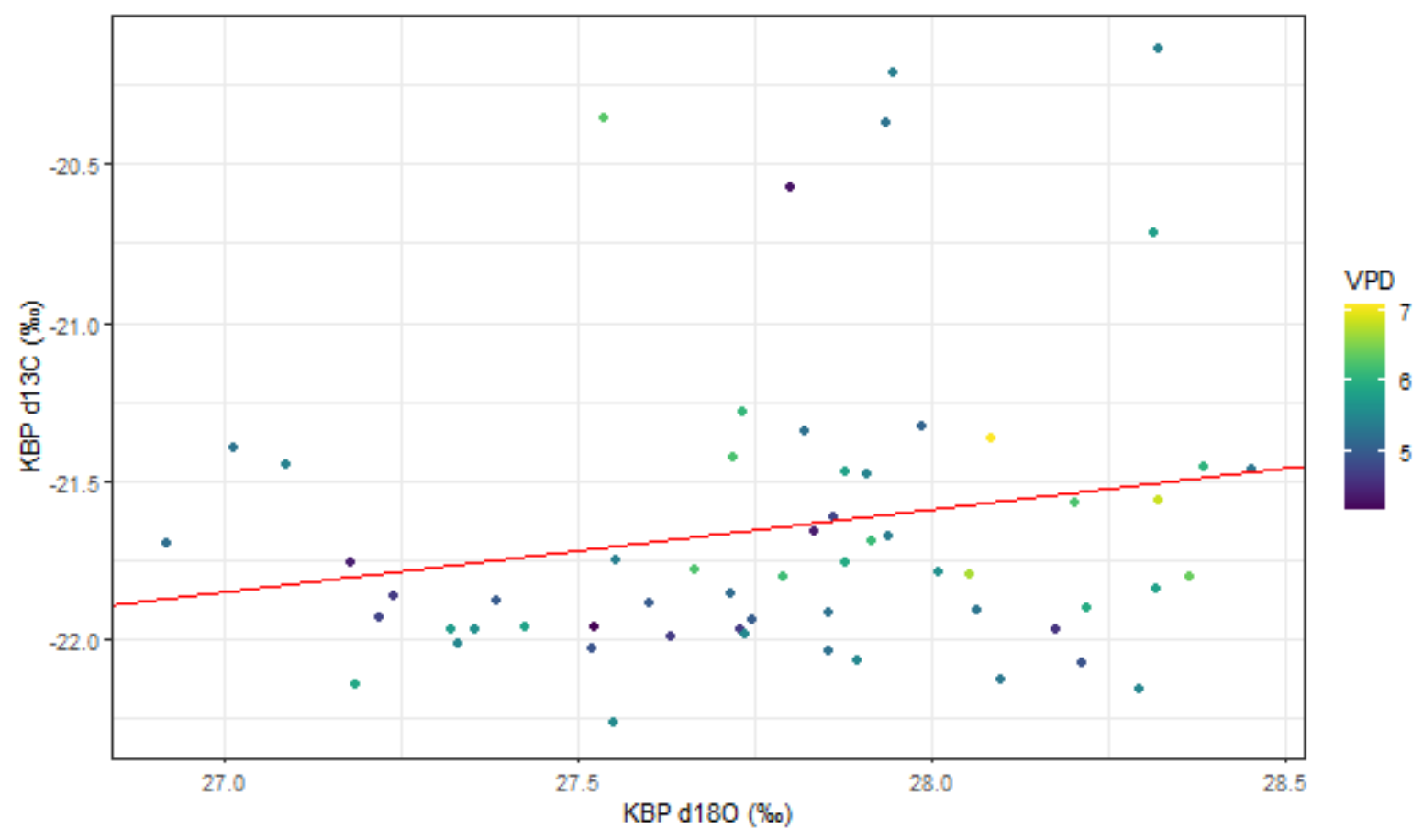

Figure 11: Direct comparison of $\delta^{18} O_{T R}$ and $\delta^{13} C_{T R}$, plotted with summer (ONDJ) VPD. Red line represents a regression line between $\delta^{18} O_{T R}$ and $\delta^{13} C_{T R}(R$-squared $=0.04, p=0.13$ )

\section{Assess Source Region Influences}

HYSPLIT backward trajectories show that Tasmania receives most of its precipitation from the West, due to prevailing westerly winds (Fig. 12). There are occasional easterlies and continental sources of precipitation, though they are infrequent and this area is much smaller than the western area of influence. The abundance of sampled trajectories that cross over each cell decreases heading west out from Tasmania. The area that has the strongest influence is immediately to the south of the mainland of Australia (south of the Great Australian Bight), with weakened influence further into the Southern and Indian oceans. Many trajectories begin in the further reaches of this range, but a large portion of them pass over the area immediately to the west of Tasmania. 


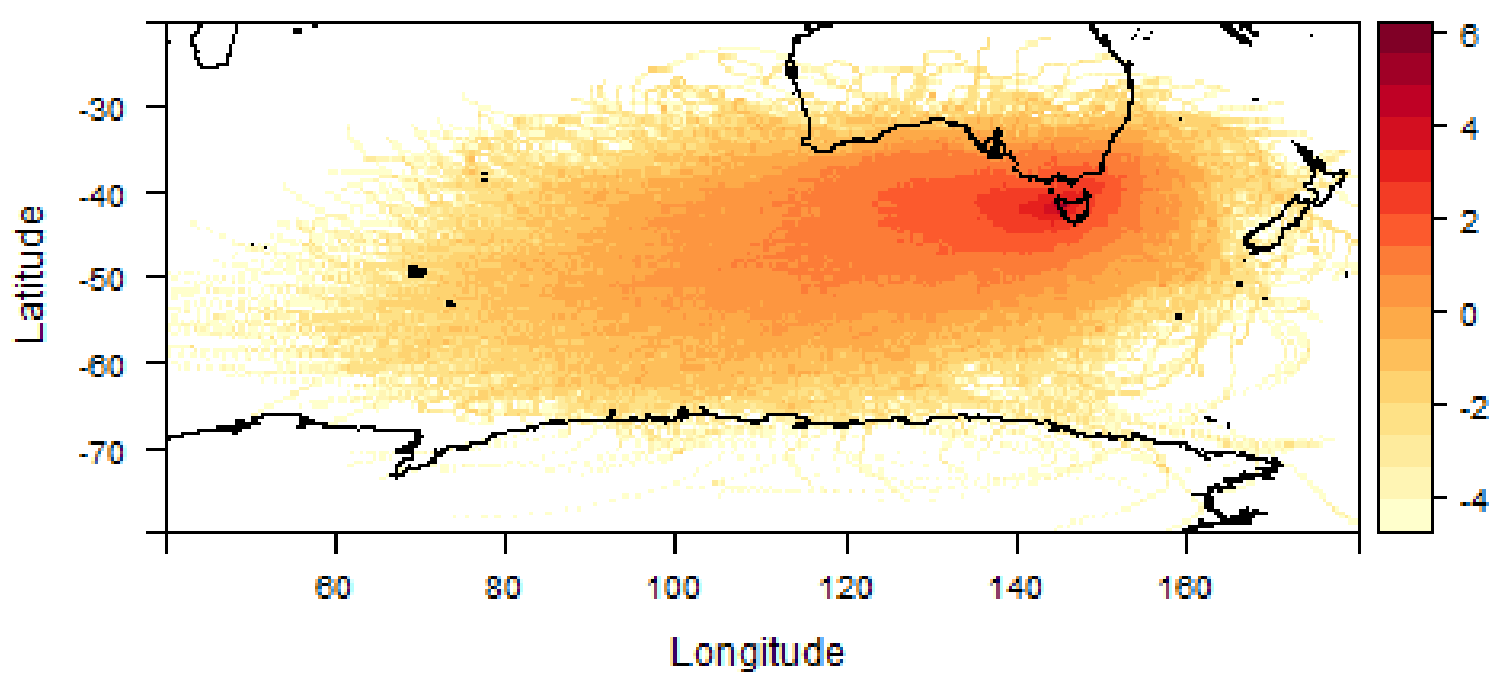

Figure 12: Summary of HYSPLIT-defined source area for September - February of 1960 - 2018. The scale represents the logtransformed number of occurrences by a trajectory point in each cell.

The difference in HYSPLIT output between the 10 most SAM+ years and the 10 most SAMyears is most prevalent in the region close to Tasmania. The range of the source region is very similar for both sets of trajectories. However, more trajectories travel near the southern coast of Australia during SAM+ years, according to the anomaly maps (Fig. 13). There is a region at 40 degrees South to the west of Tasmania that shows positive anomalies. This feature is not present during SAM- years, during which there are slightly more trajectories at $\sim-50$ degrees South to the west of Tasmania. 


\section{SAM+ Anomalies}

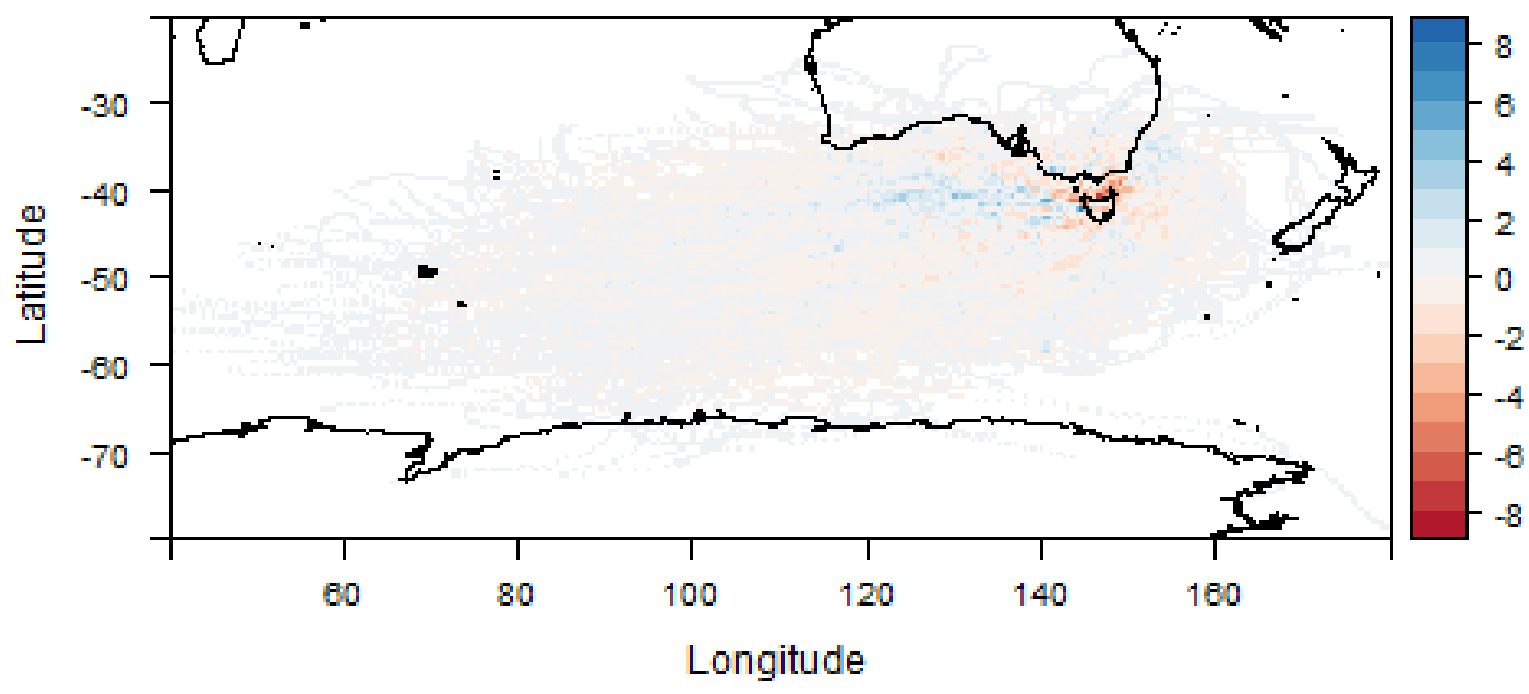

SAM- Anomalies

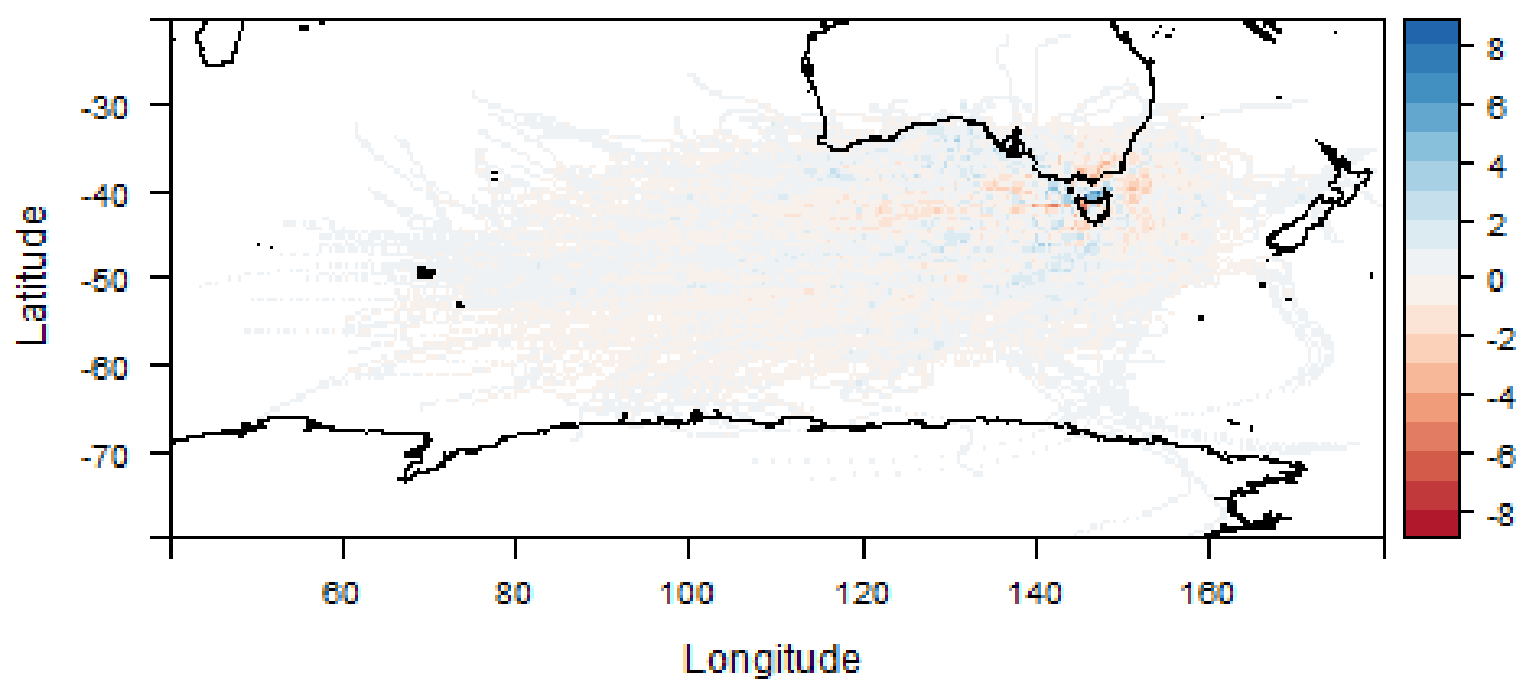

Figure 13: Comparison of anomaly plots for HYSPLIT output between 10 most SAM-positive and 10 most SAM-negative years. Positive anomalies (blue) represent areas that have a greater abundance of trajectories than the mean conditions, while negative anomalies (red) represent areas with a lower abundance of trajectories than the mean conditions.

The difference in the HYSPLIT output between the top $25 \%$ of $\delta^{18} \mathrm{O}_{\mathrm{TR}}$ years and the bottom $25 \%$ of $\delta^{18} \mathrm{O}_{\mathrm{TR}}$ years (Fig. 14) can be described similarly to the SAM anomaly output. High $\delta^{18} \mathrm{O}_{\mathrm{TR}}$ years show a consistent mid-latitude influence, whereas low $\delta^{18} \mathrm{O}_{\mathrm{TR}}$ years have more latitudinally varied influence. One notable difference, however, is that low $\delta^{18} \mathrm{O}_{\mathrm{TR}}$ years show an influence to the east of Tasmania, which is not seen in either SAM anomaly plot. 


\section{Top $25 \%$ d180 Anomalies}

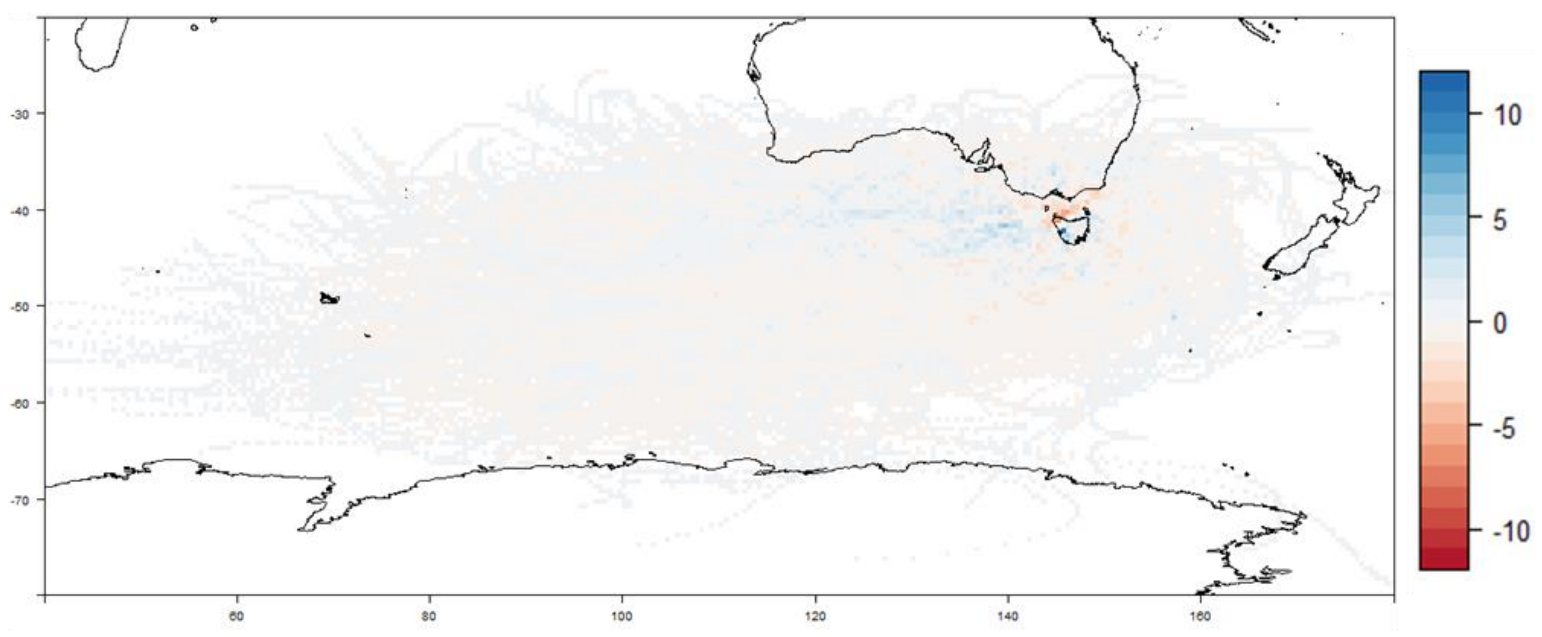

\section{Bottom 25\% d180 Anomalies}

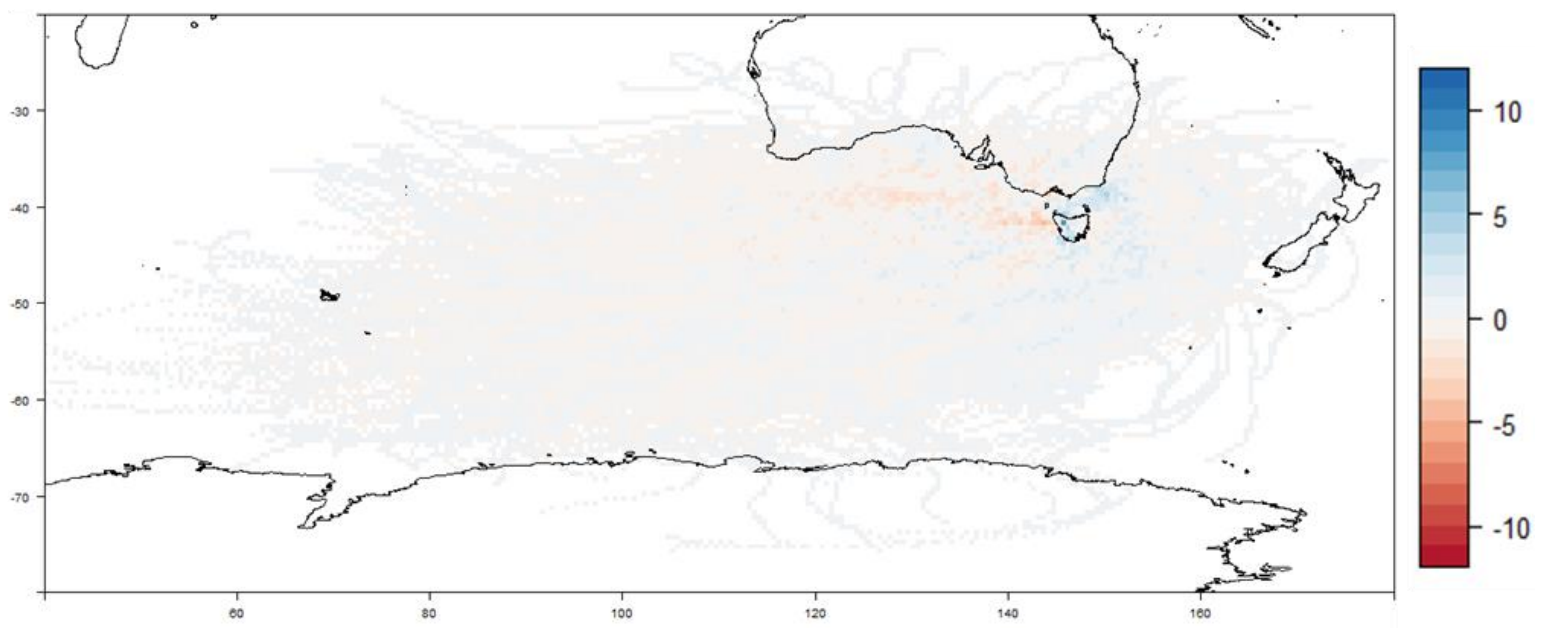

Figure 14: Comparison of anomaly plots for HYSPLIT output between the top $25 \%$ of years by median $\delta^{18} \mathrm{O}_{T R}$ and the bottom $25 \%$ of years by $\delta^{18} O_{T R}$. Positive anomalies (blue) represent areas that have a greater abundance of trajectories than the mean conditions, while negative anomalies (red) represent areas with a lower abundance of trajectories than the mean conditions.

The difference in the HYSPLIT output between the top $25 \%$ of GNIP $\delta^{18} \mathrm{O}_{\mathrm{P}}$ years and the bottom $25 \%$ of $\delta^{18} \mathrm{O}_{\mathrm{P}}$ years (Fig. 15) is slightly different from both the SAM anomalies and the $\delta^{18} \mathrm{O}_{\mathrm{TR}}$ anomalies. High $\delta^{18} \mathrm{O}_{\mathrm{P}}$ years show influence from areas close to Tasmania to the southwest, north, and northeast, whereas low $\delta^{18} \mathrm{OP}_{\mathrm{P}}$ years have northern influence below mainland Australia and a distinct lack of trajectories over Tasmania and to the south. The region to the west of Tasmania does not show consistent patterns for either high $\delta^{18} \mathrm{O}_{\mathrm{P}}$ or low $\delta^{18} \mathrm{O}_{\mathrm{P}}$. 


\section{Top 25\% GNIP Anomalies}

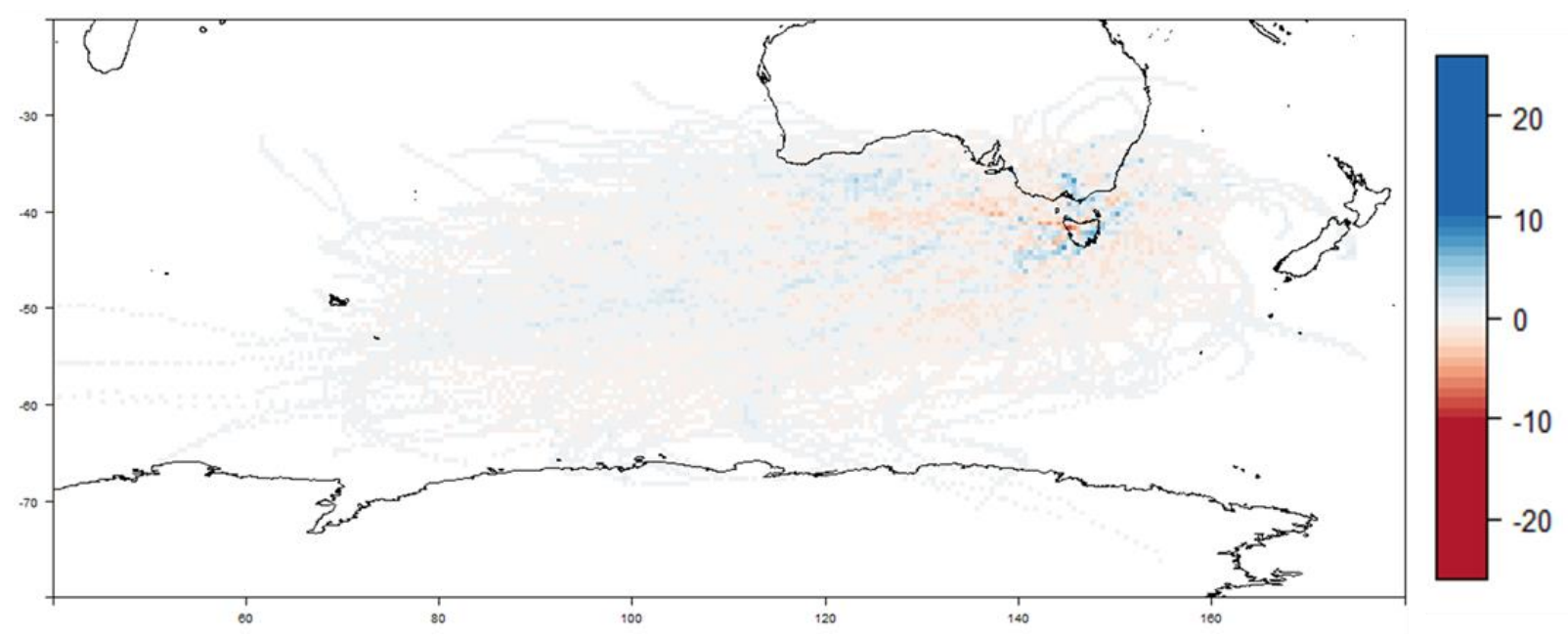

\section{Bottom 25\% GNIP Anomalies}

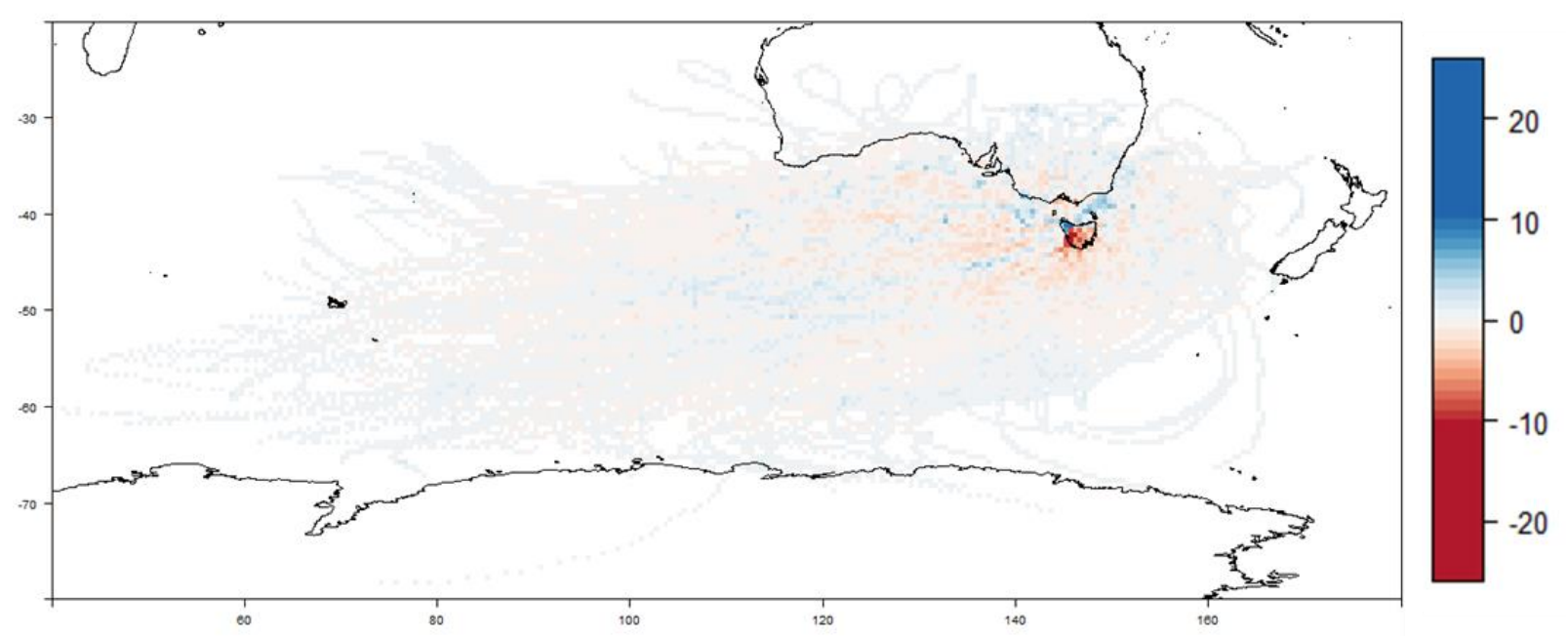

Figure 15: Comparison of anomaly plots for HYSPLIT output between the top $25 \%$ of years by GNIP $\delta^{18}$ OP for SeptemberFebruary and the bottom 25\% of years by GNIP $\delta^{18} O_{P}$ for September - February. Positive anomalies (blue) represent areas that have a greater abundance of trajectories than the mean conditions, while negative anomalies (red) represent areas with a lower abundance of trajectories than the mean conditions.

Correlations between $\delta^{18} \mathrm{O}_{\mathrm{TR}}$ and regional climate variables reveal relationships in the source region of precipitation at Mount Read. Figure 16 is masked by significance, so all cells that are colored are statistically significant $(\mathrm{p}<0.05)$. Temperature is positively correlated with $\delta^{18} \mathrm{O}_{\mathrm{TR}}$ in some areas surrounding Tasmania. The most notable areas of significance for temperature are to the west of Tasmania, south of mainland Australia $(0.2<\mathrm{r}<0.4)$, immediately to the east of Tasmania $(0.2<\mathrm{r}<0.4)$, and over the mainland of Australia $(0.3<\mathrm{r}<0.5)$.

Precipitation is negatively correlated with $\delta^{18} \mathrm{O}_{\mathrm{TR}}$ immediately surrounding Tasmania to the west, as well as to the north in mainland Australia $(-0.5<\mathrm{r}<-0.2)$. There are small areas where precipitation is slightly positively correlated with $\delta^{18} \mathrm{O}_{\mathrm{TR}}$ in the Southern Ocean $(0.2<\mathrm{r}<0.4)$. 


\section{September - February}

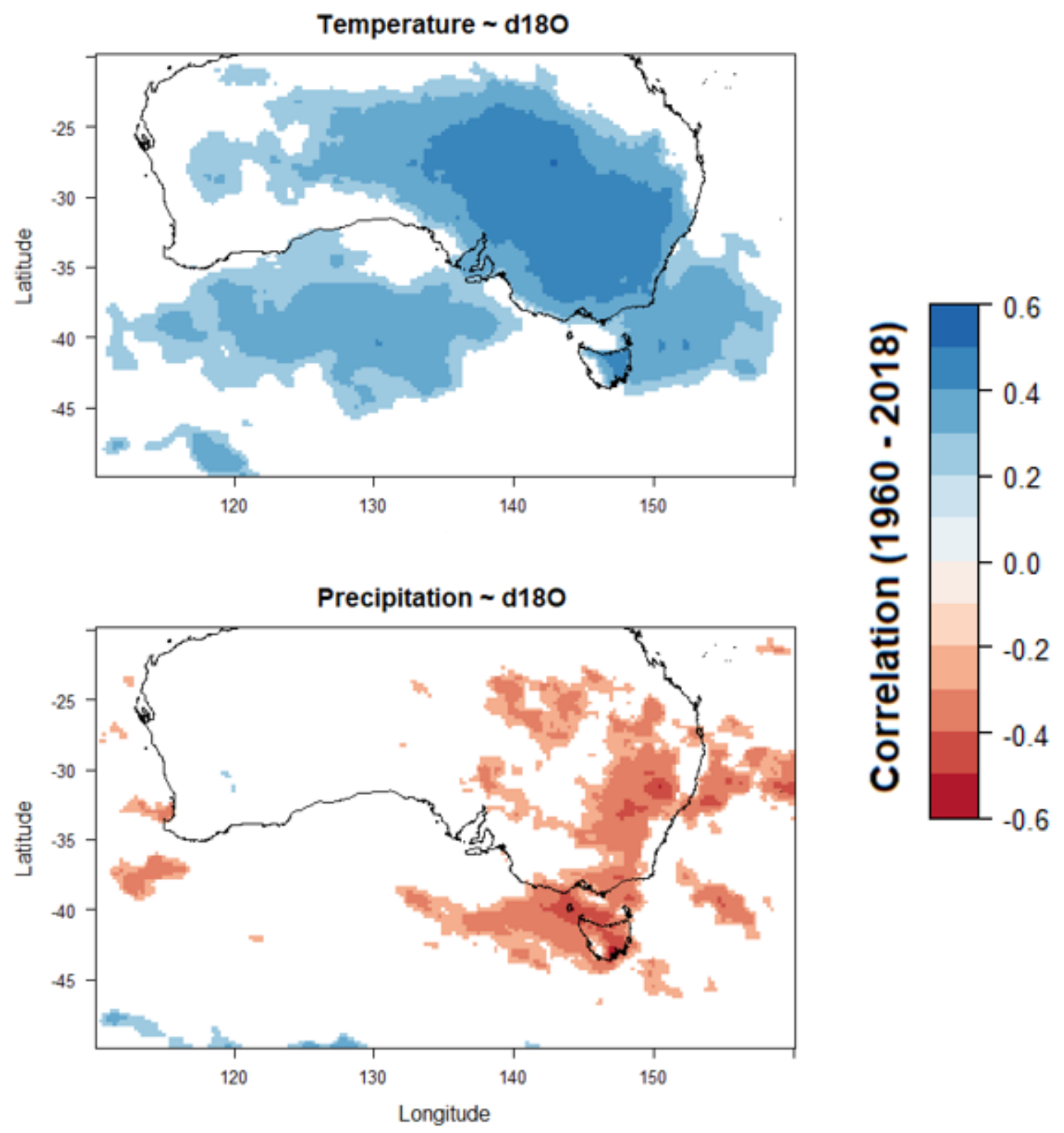

Figure 16: Spatial maps of Pearson correlations were performed between $\delta^{18} O_{T R}$ and September - February averages of ERA5 temperature at $2 m$ elevation and total precipitation. These ouput maps are masked by significance, so all cells visible are statistically significant $(p<0.05)$

Figure 17 splits the correlations from figure 16 into two separate seasons, September November (spring) and December - February (summer). Similar trends are seen between temperature and precipitation; in the spring, there is a large patch of correlation to the west of Tasmania (temperature also shows a large region of positive correlation in the mainland of Australia). In the summer, the areas that show the corresponding correlation (positive for temperature, negative for precipitation) become smaller. 


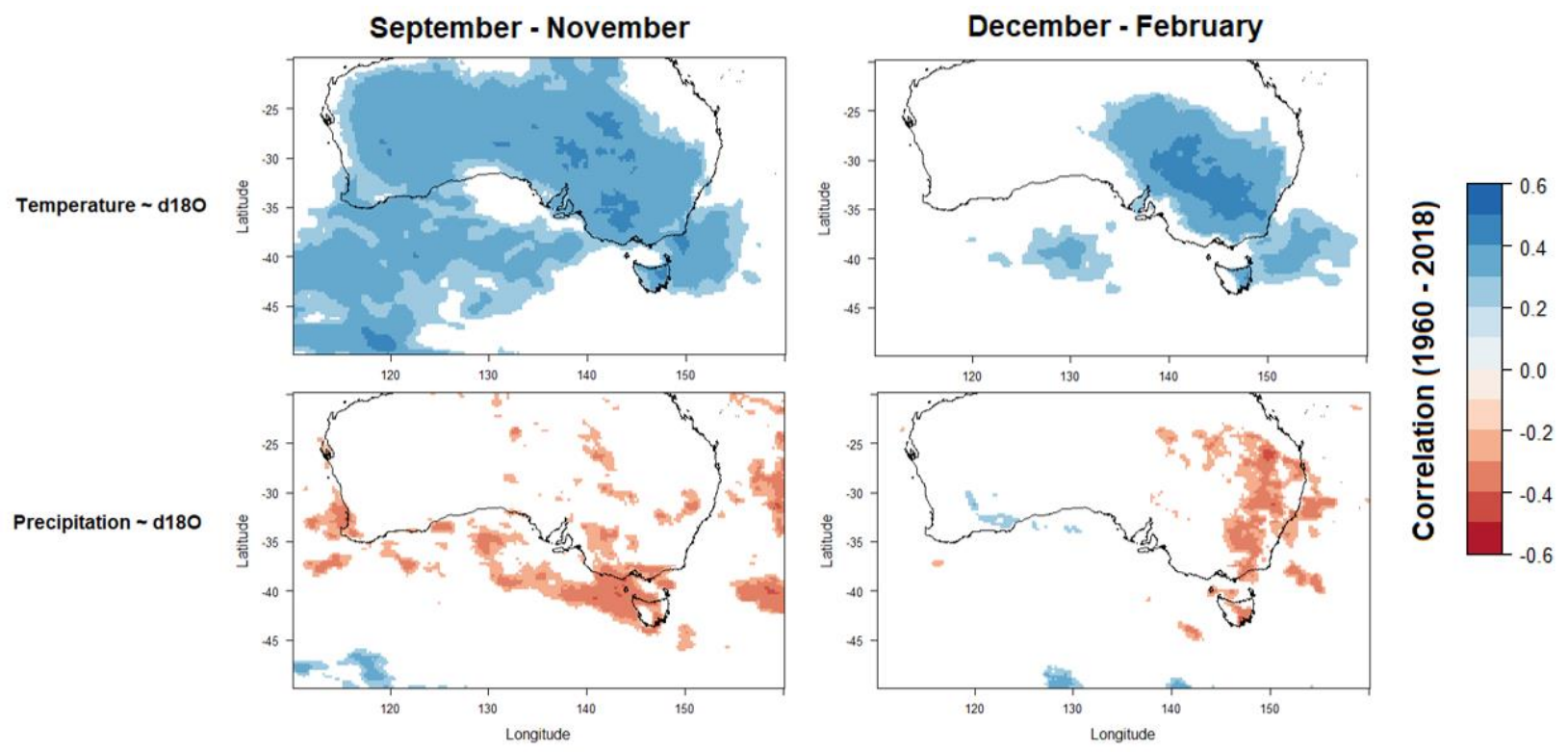

Figure 17: Spatial maps of Pearson correlations were performed between $\delta^{18} O_{T R}$ and seasonal averages of ERA5 temperature at $2 m$ elevation and total precipitation. These correlations are similar to the ones seen in figure 12, except these are averages for September - November and December - February. These output maps are masked by significance, so all cells visible are statistically significant $(p<0.05)$.

Figure 18 displays similar correlations to figure 16, however these are performed using the GNIP d180p data instead to d180tr for 1979 - 2002. The region displaying significant temperature correlations is remarkably different here, with the region to the northeast of Tasmania displaying strong $(0.4-0.7)$ correlations between temperature and GNIP d180p. Precipitations shows a similar correlation map, with strong negative correlations $(0.4-0.6)$ being present to the west of Tasmania. It is important to note that, due to the lower number of observations ( $x$ years vs. 59 ), the threshold to be considered a significant correlation $(p<0.05)$ requires a stronger relationship. 


\section{September - February}

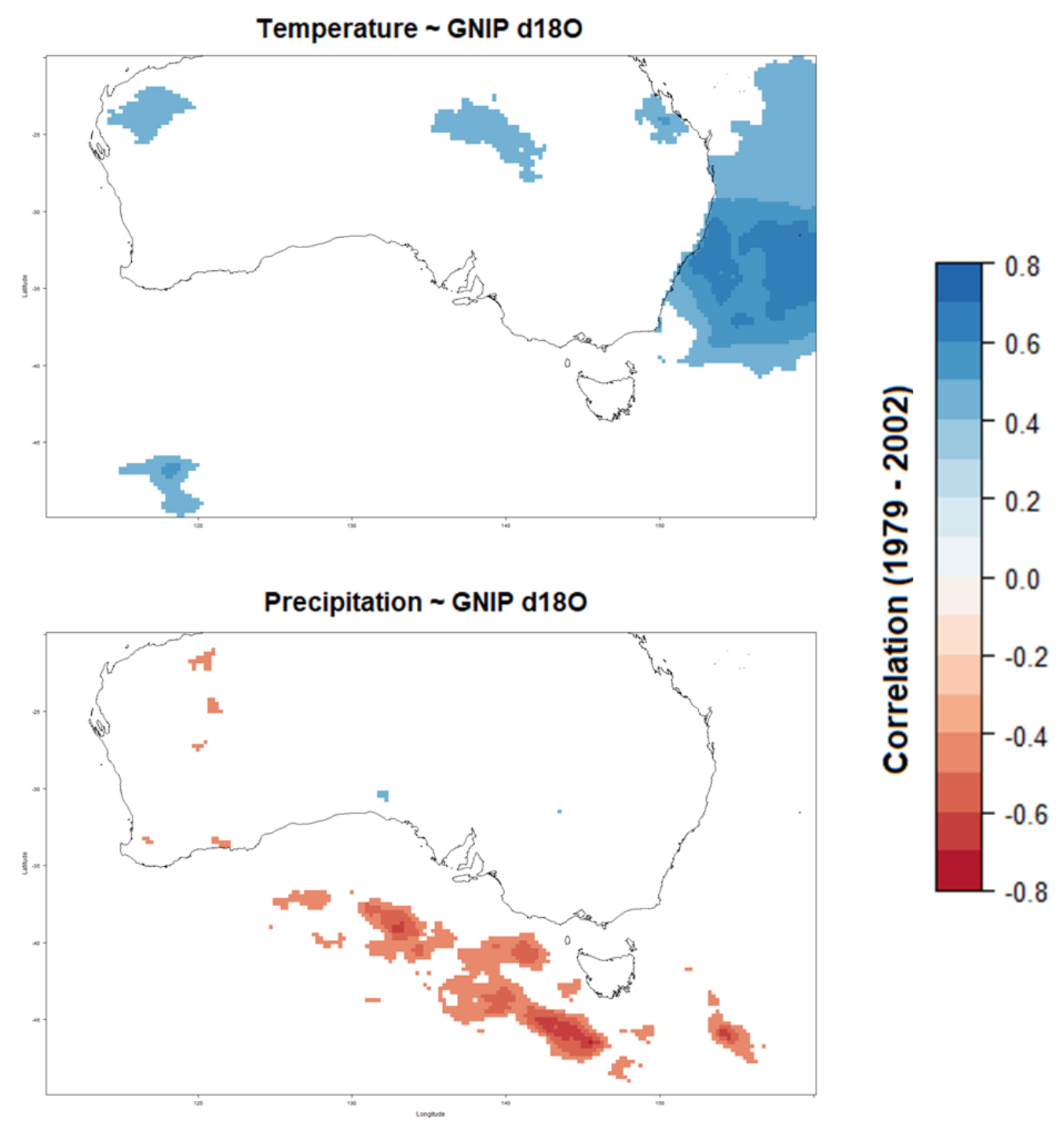

Figure 18: Spatial maps of Pearson correlations were performed between GNIP $\delta^{18} \mathrm{O}_{P}$ and September - February averages of ERA5 temperature at $2 m$ elevation and total precipitation. These ouput maps are masked by significance, so all cells visible are statistically significant $(p<0.05)$

\section{Discussion}

A common dominant control on $\delta^{18} \mathrm{O}_{\mathrm{TR}}$ is local moisture, usually measured by relative humidity (McCarroll \& Loader, 2004). In this study, site-level correlations reveal that $\delta^{18} \mathrm{O}_{\mathrm{TR}}$ is not significantly correlated with relative humidity at Mount Read over any 3-month period during from September to February (Fig. 8). However, $\delta^{18} \mathrm{O}_{\mathrm{TR}}$ is significantly correlated with VPD during October - December $(r=0.32, \mathrm{p}<0.05)$ and November - January $(r=0.27, \mathrm{p}<0.05)$. While these correlations are significant, they are weak. In addition, if local moisture was a strong influence on stable isotope ratios at Mount Read, we would expect a relationship between $\delta^{18} \mathrm{O}_{\mathrm{TR}}$ and $\delta^{13} \mathrm{C}_{\mathrm{TR}}$ like the relationship seen in Figure 1 (adapted from Scheidegger et al., 2000) where 
dry conditions cause enrichment in both $\delta^{13} \mathrm{C}_{\mathrm{TR}}$ and $\delta^{18} \mathrm{O}_{\mathrm{TR}}$ due to decreased stomatal conductance. However, as shown in Figure 11, there is no significant relationship between $\delta^{18} \mathrm{O}_{\mathrm{TR}}$ and $\delta^{13} \mathrm{C}_{\mathrm{TR}}(\mathrm{r}=0.20, \mathrm{p}>0.05)$. The relationship between $\delta^{18} \mathrm{O}_{\mathrm{TR}}$ and $\delta^{13} \mathrm{C}_{\mathrm{TR}}$ is flat. Scheidegger et al. (2000) outline a scenario where internal carbon (ci) remains constant, which indicates that stomatal conductance and photosynthetic rate are both influencing $\delta^{13} \mathrm{C}_{\mathrm{TR}}$. In this case, there would be variation in $\delta^{18} \mathrm{O}_{\mathrm{TR}}$ with little change in $\delta^{13} \mathrm{C}_{\mathrm{TR}}$, which is similar to the relationship observed in these data. While there is a weak positive correlation between $\delta^{18} \mathrm{O}_{\mathrm{TR}}$ and VPD, there is no correlation between $\delta^{13} \mathrm{C}_{\mathrm{TR}}$ and VPD or relative humidity between September and February (Fig. 8). Further, $\delta^{13} \mathrm{C}_{\mathrm{TR}}$ is not significantly correlated to any local climate conditions. If VPD were strongly influential in controlling stomatal conductance at the site, then this should be reflected in both the $\delta^{13} \mathrm{C}_{\mathrm{TR}}$ and $\delta^{18} \mathrm{O}_{\mathrm{TR}}$ series. Instead, VPD influences only $\delta^{18} \mathrm{O}_{\mathrm{TR}}$, indicating that the influence of local moisture is either weak and/or does not influence stomatal conductance enough to register with $\delta^{13} \mathrm{C}_{\mathrm{TR}}$. The Scheidegger et al. (2000) model assumes that source water $\delta^{18} \mathrm{O}_{\mathrm{P}}$ is constant; however, this is not always the case (Roden $\&$ Farquhar, 2012). Spatial correlations suggest that $\delta^{18} \mathrm{OP}$ varies with changes in temperature and precipitation (Fig. 16). Local moisture is influential, though not strong enough to be the dominant factor influencing $\delta^{18} \mathrm{O}_{\mathrm{TR}}$.

Consistent with other studies (Lavergne et al., 2016; Porter et al., 2014; Grießinger et al., 2014), local temperature is significantly positively correlated with $\delta^{18} \mathrm{O}_{\mathrm{TR}}$ in the early growing season (October - December $r=0.27, p<0.05$ ). It is possible that this correlation is a product of a seasonal effect: precipitation that falls in October - December is the water that is incorporated into the wood later in the growing season. $\delta^{18} \mathrm{O}_{\mathrm{TR}}$ also shows a positive correlation with solar radiation for September - February $(r=0.26, p<0.05)$. Solar radiation can influence $\delta^{13} C_{\text {TR }}$ due to increases in photosynthetic rate; however, solar radiation is not commonly thought to influence $\delta^{18} \mathrm{O}_{\text {TR }}$ (McCarroll \& Loader, 2004). This may be a spurious correlation as a result of a confounding variable. $\delta^{18} \mathrm{O}_{\text {TR }}$ is correlated with local temperature, which is also correlated with irradiance. As a result, $\delta^{18} \mathrm{O}_{\text {TR }}$ shows a positive correlation with solar radiation, even though no mechanisms that control $\delta^{18} \mathrm{O}_{\text {TR }}$ are strongly influenced by solar radiation.

The spatial correlations for September - February reveal which regions are influential in determining $\delta^{18} \mathrm{O}_{\mathrm{TR}}$ of $A$. selaginoides. $\delta^{18} \mathrm{O}_{\mathrm{TR}}$ shows a positive relationship with temperature in the Indian Ocean immediately to the south of mainland Australia $\left(35-45^{\circ} \mathrm{S}, 110-140^{\circ} \mathrm{E}\right)$, which is expected. For precipitation, there is an area of strong negative correlation immediately to the west of Tasmania, slightly further east $\left(40-45^{\circ} \mathrm{S}, 135-145^{\circ} \mathrm{E}\right)$ than the region of correlation for temperature. A negative relationship between $\delta^{18} \mathrm{O}_{\mathrm{Tr}}$ and precipitation amount along the path of moisture delivery to the site is also to be expected, due to Rayleigh distillation and the amount effect (Dansgaard, 1964). The HYSPLIT sampling of backward trajectories (Fig. 12) for 1960 2018 suggests that this region of the Indian Ocean to the south of mainland Australia is the most common source region of precipitation $\left(35-45^{\circ} \mathrm{S}, 110-150^{\circ} \mathrm{E}\right)$ at Mount Read. The pair of relationships with temperature and precipitation combined with the HYSPLIT output provide some insight into the dynamics that influence $\delta^{18} \mathrm{OP}_{\mathrm{P}}$ of the source water to A. selaginoides at Mount Read. Water vapor forms over the Indian Ocean in the region where temperature shows a positive relationship with $\delta^{18} \mathrm{O}_{\mathrm{TR}}$; as the HYSPLIT output would suggest, this is a common occurrence. This moisture travels east, passing over the region where precipitation shows a 
negative relationship with $\delta^{18} \mathrm{O}_{\mathrm{TR}}$, eventually passing Mount Read as well. The temperature in the initial area of vapor formation influences the initial $\delta^{18} \mathrm{O}$ of the water vapor. If this vapor mass has any precipitation events on its path to Mount Read, the subsequent vapor mass and precipitation events will be more depleted. $\delta^{18} \mathrm{O}_{\mathrm{P}}$ at Mount Read is influenced by this chain of events, and thus temperature and precipitation in this region are reflected by $\delta^{18} \mathrm{O}_{\mathrm{TR}}$. This process also aligns with the idea that, due to the prevailing westerly winds in the mid-latitudes, much of the precipitation at Mount Read comes from the west, along the path defined by the HYSPLIT analysis. The strength of the correlations with temperature $(0.2<\mathrm{r}<0.4)$ and precipitation $(0.2<$ $r<0.5)$ suggests that variation in $\delta^{18} \mathrm{O}_{\mathrm{P}}$ coming from the west influences $\delta^{18} \mathrm{O}_{\mathrm{TR}}$ at Mount Read.

Despite prevailing westerly winds, Tasmania experiences occasional easterly winds (Hendon et al., 2007). A smaller region immediately to the east of Tasmania also shows a positive correlation between temperature and $\delta^{18} \mathrm{O}_{\mathrm{TR}}$ and is a common source region according to the HYSPLIT results (Fig. 12). It is possible that this region is also a source of precipitation at Mount Read, following the same dynamics present in the source region to the west. This source region is smaller and does not extend far into the ocean, suggesting that this vapor forms and rains out closer to Tasmania; therefore, the corresponding negative correlation with precipitation is not over the ocean, but rather over Tasmania itself. There is also a significant positive relationship between $\delta^{18} \mathrm{O}_{\mathrm{TR}}$ and temperature over the mainland of Australia. As evidenced by the HYSPLIT backward trajectories, the mainland is not a common source region of air masses for Mount Read (Fig. 12), though it is possible that there are occasional sources of precipitation from mainland Australia that are highly enriched after forming over a lower latitude land surface.

The weak relationship between local moisture conditions and $\delta^{18} \mathrm{O}_{\mathrm{TR}}$ supports the idea that variation in $\delta^{18} \mathrm{O}_{\mathrm{P}}$ significantly influences $\delta^{18} \mathrm{O}_{\mathrm{TR}}$ at Mount Read. High precipitation at Mount Read (Fig. 5) serves to strengthen the relationship between $\delta^{18} \mathrm{O}_{\mathrm{P}}$ and $\delta^{18} \mathrm{O}_{\mathrm{TR}}$ due to less fractionation at the site (Treydte et al., 2014). In addition, abundant moisture at the site leads to less variation in relative humidity, and thus stomatal conductance may not be low enough to impact the $\delta^{18} \mathrm{O}_{\mathrm{TR}}$ signal very often. While there is a significant relationship between $\delta^{18} \mathrm{O}_{\mathrm{TR}}$ and VPD, introduced by either controlling stomatal conductance or evaporative enrichment of soil water, it is weak enough that it does not significantly diminish the relationship between the source water and $\delta^{18} \mathrm{O}_{\mathrm{TR}}$.

There are multiple seasonal relationships observed between local and source region climate variables with $\delta^{18} \mathrm{O}_{\mathrm{TR}}$ that are difficult to reconcile. Spatial correlations with temperature and precipitation imply that the early growing season is the most influential season for determining the $\delta^{18} \mathrm{O}_{\mathrm{TR}}$ signal, as Figure 17 shows that in September - November, the regions showing strong correlation are much larger than in December - February. However, other data such as the GNIP $\delta^{18} \mathrm{OP}_{\mathrm{P}}$ measurements imply that the commonly accepted summer growing season is the most influential for oxygen incorporation (Fig. 9). It is possible that the precipitation formed in the spring is the water that is used by the trees during the growing season, which would suggest that there is a lengthy residence time of water in the soil or in the tree before it is incorporated (Treydte et al., 2014). Another possibility is that the growing season of A. selaginoides is not the commonly accepted December - February, but rather begins slightly earlier. This would explain the weakened strength of correlations in December-February. However, both scenarios conflict 
with the strong correlation between $\delta^{18} \mathrm{O}_{\mathrm{TR}}$ and GNIP $\delta^{18} \mathrm{O}_{\mathrm{P}}$ in the November - January season ( $\mathrm{r}$ $=0.55)$. The relationship with GNIP $\delta^{18} \mathrm{O}_{\mathrm{P}}$ could be in question, since GNIP is not measured at Mount Read, but rather nearby Cape Grim, which is a much lower altitude $(86 \mathrm{~m})$ than Mount Read $(1123 \mathrm{~m})$, and higher altitude sites receive more depleted $\delta^{18} \mathrm{O}_{\mathrm{P}}$ than lower altitude sites (Dansgaard, 1964). In addition, there is a limited number of observations available for GNIP ( $\mathrm{n}=$ 21). The plot shown in Figure 9 indicates that the relationship between $\delta^{18} \mathrm{O}_{\mathrm{TR}}$ and GNIP $\delta^{18} \mathrm{OP}_{\mathrm{P}}$ may be driven by only a few data points. It is possible that vapor forms in October-November, travels to Tasmania and falls in November-December, which could suggest that both relationships are valid. However, the 120-hour backward trajectories produced in Figure 12 imply a much shorter travel time for these air masses.

There is high inter-tree variation within the $\delta^{18} \mathrm{O}_{\mathrm{TR}}$ data relative to the ring width chronology. Low EPS (0.566) and rbar (0.13) for the $\delta^{18} \mathrm{O}_{\mathrm{TR}}$ series indicate that the trees do not share strong year-to-year correlations (Table 3 ). The average range in values for each year is $2.68 \%$ o (standard deviation $=0.91 \%$ ). For this reason, I used the median $\delta^{18} \mathrm{O}_{\mathrm{TR}}$ value for each year instead of the mean, as it reduces the effect of outliers. As shown in Figure 7, variation is higher in the early years of the study period ( $1960-1995)$ than the later years $(\sim 1996-2018)$. This variability makes annual trends difficult to parse. I attempted to resolve the source of this variability by correlating individual tree means and standard deviations with local conditions we measured while sampling; however, this produced no significant correlations (Appendix 1). The paired $\delta^{13} \mathrm{C}_{\mathrm{TR}}$ measurements have much higher EPS (0.791) and rbar (0.318). If the variation in $\delta^{18} \mathrm{O}_{\mathrm{TR}}$ was the result of an error in sample processing, then this variation would also be present in the $\delta^{13} \mathrm{C}_{\mathrm{TR}}$ series. The source of variability between trees is most likely climatic conditions or a physiological trait in $A$. selaginoides that allows trees to not photosynthesize at the same time. Significant first-order (0.319) and second-order (0.273) autocorrelation values imply that there could be some influence of water storage from previous years, which could contribute to variability between trees. However, these values are quite low even if they are significant, so it is unlikely that these values are driving variability in $\delta^{18} \mathrm{O}_{\mathrm{TR}}$ between trees. It is also possible that heterogeneous topography at the site contributes to this variability.

Correlations with climate variables using the between-tree variability in $\delta^{18} \mathrm{O}_{\mathrm{TR}}$ (standard deviation) reveal that $\delta^{18} \mathrm{O}_{\mathrm{TR}}$ variability is negatively correlated with solar radiation, temperature, and VPD during the early growing season (Fig. 10). This relationship would imply that variation in $\delta^{18} \mathrm{O}_{\mathrm{TR}}$ decreases in a warmer, dryer climate. One possible physiological explanation for this is that variation between trees is mainly introduced by stomatal conductance. In warm and dry conditions, the $A$. selaginoides trees could be behaving more similarly to each other because there is not as much leaf water enrichment via the Péclet effect (Barbour et al., 2004). The source water signal receives the same treatment by all trees in this case, leading to less variation in $\delta^{18} \mathrm{O}_{\text {TR. }}$ Under cool and wet conditions (which are common on Mount Read due to high precipitation), the source water delivery is altered by individual-tree processes, and factors such as rooting depth may alter the $\delta^{18} \mathrm{O}_{\mathrm{TR}}$ values, resulting in higher variation in $\delta^{18} \mathrm{O}_{\mathrm{TR}}$. One possible way to test for this would be to split the chronology where variation changes $(\sim 1995)$ and perform the spatial correlations on the two groups. If there is more correlation in the later years where variation is lower, this would imply that $\delta^{18} \mathrm{O}_{\mathrm{TR}}$ closely reflects the signal of the source water under these conditions. 
The HYSPLIT sampling hints at a possible influence of the SAM on the source region of precipitation at Mount Read. During positive SAM years, there is a distinctive trail at $\sim 41^{\circ} \mathrm{S}$ where positive anomalies show an abundance of backward trajectories. This trail is not present during the negative SAM years (Fig. 13). These results could imply a consistent mid-latitude influence during strongly positive SAM years, whereas negative SAM years have a more varied distribution of trajectories with more influence from higher latitudes near the Southern Ocean. SAM has been trending positive over the past 60 years (Marshall, 2003), which would imply that mid-latitude trajectories are more common later in the study period. A distinctive difference in trajectories between positive SAM and negative SAM years would have implications for the $\delta^{18} \mathrm{O}_{\text {TR }}$ signal at Mount Read. Negative SAM years display a latitudinally wider range of moisture sources than positive SAM years (Fig. 13). A high-latitude moisture source would be more depleted in $\delta^{18} \mathrm{O}$, as vapor from colder regions is more depleted (Dansgaard, 1964). I would hypothesize that, during SAM years, the $\delta^{18} \mathrm{O}_{\mathrm{TR}}$ signal would have greater variation and would be slightly more depleted than positive SAM years, due to the difference in source region, and I would expect spatial correlation maps for these two groups to be different. This is supported by the HYSPLIT anomalies by $\delta^{18} \mathrm{O}_{\mathrm{TR}}$, which show similar patterns to the SAM anomalies (Fig. 14). A strong mid-latitude influence is associated with both positive SAM conditions and increased $\delta^{18} \mathrm{O}_{\mathrm{TR}}$, which could imply that the SAM is influencing the $\delta^{18} \mathrm{O}_{\mathrm{TR}}$ signal. While these patterns are interesting, there is no significant correlation between $\delta^{18} \mathrm{O}_{\text {TR }}$ and the SAM index for September - February over the study period. Further research is needed to investigate the moisture delivery conditions associated with both positive SAM and increased $\delta^{18} \mathrm{O}_{\text {TR }}$.

Differences in the spatial correlations and HYSPLIT anomalies between the GNIP $\delta^{18} \mathrm{OP}_{\mathrm{P}}$ dataset and the $\delta^{18} \mathrm{O}_{\text {TR }}$ measurements imply that different moisture sources may be influencing these measurements. The spatial correlations for GNIP (Fig. 18) imply that moisture to the northeast of Tasmania is influential in determining the $\delta^{18} \mathrm{O}_{\mathrm{P}}$ signal, while the area to the west is insignificant. The spatial correlations for $\delta^{18} \mathrm{O}_{\mathrm{TR}}$ (Fig. 16) show that the area to the west of Tasmania is the most significant region, and while there is some eastern influence it is not nearly as strong as seen in the $\delta^{18} \mathrm{O}_{\mathrm{P}}$ correlations. It is possible that moisture that originates in the northeast, while more infrequent, is more enriched in $\delta^{18} \mathrm{O}$ than most moisture delivered to Tasmania, and the strong $\delta^{18} \mathrm{O}_{\mathrm{P}}$ value is measured in the GNIP dataset. However, this precipitation would mix with moisture storage already present at Mount Read, and much of it would run off before being incorporated into the trees, resulting in a more muted influence on the $\delta^{18} \mathrm{O}_{\text {TR }}$ signal. However, the HYSPLIT anomalies by GNIP do not show a strong northeastern influence associated with high $\delta^{18} \mathrm{O}_{\mathrm{P}}$ (Fig. 15). In addition, some of this variation could be because GNIP data are measured at Cape Grim, which is near Mount Read but not the same location.

The local correlations reveal that $\delta^{18} \mathrm{O}_{\mathrm{TR}}$ is significantly correlated with precipitation in January $-\operatorname{March}(\mathrm{r}=0.26, \mathrm{p}<0.05)$. This correlation is unusual because $\delta^{18} \mathrm{O}_{\mathrm{TR}}$ is generally not thought to be positively related to total precipitation (McCarroll and Loader, 2004). There is often no relationship, and in some cases a negative relationship. In addition, this correlation occurs during a period where no other climate measure is significantly correlated with $\delta^{18} \mathrm{O}_{\mathrm{TR}}$. The combination of these factors combined with the relatively weak relationship leads me to believe that this is a spurious correlation. However, it is possible that high amounts of precipitation in the mid- to late-growing season are indicative of some other climate process that would influence $\delta^{18} \mathrm{O}_{\mathrm{TR}}$. 
For instance, high precipitation could be a result of negative SAM conditions which encourage more rainfall in western Tasmania (Meneghini et al., 2007; Hendon et al., 2007). As discussed, negative SAM could also result in a latitudinally varied moisture source for Mount Read, which could impact the $\delta^{18} \mathrm{O}_{\mathrm{TR}}$ signal. Further research is required to investigate any link in these processes.

\section{Conclusions}

$\delta^{18} \mathrm{O}_{\mathrm{TR}}$ in A. selaginoides at Mount Read demonstrates weak correlations to local climate measures, while having slightly stronger correlations with regional climate measures. The weak local controls on $\delta^{18} \mathrm{O}_{\text {TR }}$ are likely due to high precipitation at Mount Read, resulting in high moisture levels at the site, which serves to strengthen the relationship between $\delta^{18} \mathrm{OP}_{\mathrm{P}}$ and $\delta^{18} \mathrm{O}_{\text {TR }}$. The spatial distribution of the regional correlations makes sense given the modeled source region, though the relationships are not strong. Given the variability between samples and relatively weak relationships with climate variables, $\delta^{18} \mathrm{O}_{\mathrm{TR}}$ at Mount Read cannot be used as a proxy for paleoclimate on its own. However, the $\delta^{18} \mathrm{O}_{\text {TR }}$ series shows sensitivity to local temperature and VPD, as well as regional temperature and precipitation, meaning that $\delta^{18} \mathrm{O}_{\mathrm{TR}}$ in A. selaginoides may have potential to support paleoclimate reconstructions when combined with other proxies in the region. While the $\delta^{13} \mathrm{C}_{\mathrm{TR}}$ series has much less variability than the $\delta^{18} \mathrm{O}_{\mathrm{TR}}$ series, it does not show any relationships to local climate variables, which implies that it does not have much potential to support paleoclimate reconstructions, except as a tool to help further analyze the $\delta^{18} \mathrm{O}_{\text {TR }}$ series.

The backward trajectories produced by the HYSPLIT model demonstrate that the most influential source region of precipitation at Mount Read is to the west of Tasmania, due to the mid-latitude westerly winds. The SAM influences the source region of precipitation as well, as positive SAM conditions are marked by a distinct mid-latitude trajectory path which is not present under negative SAM conditions. Given the sensitivity of the $\delta^{18} \mathrm{O}_{\mathrm{TR}}$ series to variations in $\delta^{18} \mathrm{O}_{\mathrm{P}}$, it is possible that paleoclimate reconstructions involving $\delta^{18} \mathrm{O}_{\mathrm{TR}}$ at Mount Read could measure historical variation in the SAM. Further research is necessary to confirm any influence that the SAM has on the $\delta^{18} \mathrm{O}_{\mathrm{TR}}$ signal in A. selaginoides.

\section{References}

Abram, N. J., Mulvaney, R., Vimeux, F., Phipps, S. J., Turner, J., \& England, M. H. (2014). Evolution of the Southern Annular Mode during the past millennium. Nature Climate Change, 4(7), 564-569.

Allen, K., Drew, D. M., Downes, G. M., Evans, R., Baker, P., \& Grose, M. (2012). Ring width, climate and wood density relationships in two long-lived Tasmanian tree species. Dendrochronologia, 30(2), 167-177.

Allen, K. J., Fenwick, P., Palmer, J. G., Nichols, S. C., Cook, E. R., Buckley, B. M., \& Baker, P. J. (2017). A 1700-year Athrotaxis selaginoides tree-ring width chronology from southeastern Australia. Dendrochronologia, 45, 90-100. 
Allen, K.J., S.C. Nichols, R. Evans, S. Allie, G. Carson, F. Ling, E.R. Cook, G. Lee, P.J. Baker. (2017). A 277 year cool season dam inflow reconstruction for Tasmania, southeastern Australia. Water Resources Research, 53(1), 400-414.

Andreu-Hayles, L., Levesque, M., Martin-Benito, D., Huang, W., Harris, R., Oelkers, R., Leland, C., Martin-Fernández, J., Anchukaitis, K.J. and Helle, G. (2019). A high yield cellulose extraction system for small whole wood samples and dual measurement of carbon and oxygen stable isotopes. Chemical Geology, 504, 53-65.

Barbour, M. M., Roden, J. S., Farquhar, G. D., \& Ehleringer, J. R. (2004). Expressing leaf water and cellulose oxygen isotope ratios as enrichment above source water reveals evidence of a Péclet effect. Oecologia, 138(3), 426-435.

Bell, B., Hersbach, H., Berrisford, P., Dahlgren, P., Horányi, A., Muñoz Sabater, J., Nicolas, J., Radu, R., Schepers, D., Simmons, A., Soci, C., Thépaut, J-N. (2020): ERA5 monthly averaged data on single levels from 1950 to 1978 (preliminary version). Copernicus Climate Change Service (C3S) Climate Data Store (CDS). https://cds.climate.copernicusclimate.eu/cdsapp\#!/dataset/reanalysis-era5-single-levels-monthly-means-preliminary-backextension?tab=overview

Boswijk, G., Fowler, A., Lorrey, A., Palmer, J., \& Ogden, J. (2006). Extension of the New Zealand kauri (Agathis australis) chronology to 1724 BC. The Holocene, 16(2), 188-199.

Brendel, O., Iannetta, P. P. M., \& Stewart, D. (2000). A rapid and simple method to isolate pure alpha-cellulose. Phytochemical Analysis: An International Journal of Plant Chemical and Biochemical Techniques, 11(1), 7-10.

Bureau of Meteorology (n.d.). Climate statistics for Australian locations. http://www.bom.gov.au/climate/averages/tables/cw_097085.shtml

Cai, W., Van Rensch, P., Borlace, S., \& Cowan, T. (2011). Does the Southern Annular Mode contribute to the persistence of the multidecade-long drought over southwest Western Australia?. Geophysical Research Letters, 38(14).

Cook, E., Bird, T., Peterson, M., Barbetti, M., Buckley, B., D'Arrigo, R., Francey, R., \& Tans, P. (1991). Climatic change in tasmania inferred from a 1089-year tree-ring chronology of huon pine. Science, 253(5025), 1266-1268.

Cook, E. R., \& Peters, K. (1997). Calculating unbiased tree-ring indices for the study of climatic and environmental change. The Holocene, 7(3), 361-370.

Cullen, P. J. (1987). Regeneration patterns in populations of Athrotaxis selaginoides D. Don. from Tasmania. Journal of Biogeography, 14(1), 39-51.

Dätwyler, C., Neukom, R., Abram, N. J., Gallant, A. J., Grosjean, M., Jacques-Coper, M., Karoly, D., \& Villalba, R. (2018). Teleconnection stationarity, variability and trends of the Southern Annular Mode (SAM) during the last millennium. Climate dynamics, 51(5-6), 23212339. 
Dansgaard, W. (1964). Stable isotopes in precipitation. Tellus, 16(4), 436-468.

Dee, S., Emile-Geay, J., Evans, M. N., Allam, A., Steig, E. J., \& Thompson, D. M. (2015). PRYSM: An open-source framework for PRoxY System Modeling, with applications to oxygen-isotope systems. Journal of Advances in Modeling Earth Systems, 7(3), 1220-1247.

Duffy, J. E., McCarroll, D., Barnes, A., Ramsey, C. B., Davies, D., Loader, N. J., Miles, D., \& Young, G. H. (2017). Short-lived juvenile effects observed in stable carbon and oxygen isotopes of UK oak trees and historic building timbers. Chemical Geology, 472, 1-7.

Edwards, T. W., Wolfe, B. B., \& Macdonald, G. M. (1996). Influence of changing atmospheric circulation on precipitation $\delta 180$-temperature relations in Canada during the Holocene. Quaternary Research, 46(3), 211-218.

Ehleringer, J. R., \& Dawson, T. E. (1992). Water uptake by plants: perspectives from stable isotope composition. Plant, cell \& environment, 15(9), 1073-1082.

Evans, M. N., Tolwinski-Ward, S. E., Thompson, D. M., \& Anchukaitis, K. J. (2013). Applications of proxy system modeling in high resolution paleoclimatology. Quaternary science reviews, 76, 16-28.

Fogt, R. L., Bromwich, D. H., \& Hines, K. M. (2011). Understanding the SAM influence on the South Pacific ENSO teleconnection. Climate Dynamics, 36(7-8), 1555-1576.

Foroozan, Z., Grießinger, J., Pourtahmasi, K., \& Bräuning, A. (2019). Evaluation of Different Pooling Methods to Establish a Multi-Century $\delta 180$ Chronology for Paleoclimate Reconstruction. Geosciences, 9(6), 270.

Fritts, H. C. (1976). Tree rings and climate. Academic Press Inc., London.

Fu, P. L., Grießinger, J., Gebrekirstos, A., Fan, Z. X., \& Bräuning, A. (2017). Earlywood and latewood stable carbon and oxygen isotope variations in two pine species in southwestern China during the recent decades. Frontiers in Plant Science, 7, 2050

Gagen, M., McCarroll, D., \& Edouard, J. L. (2004). Latewood width, maximum density, and stable carbon isotope ratios of pine as climate indicators in a dry subalpine environment, French Alps. Arctic, Antarctic, and Alpine Research, 36(2), 166-171.

Gagen, M., McCarroll, D., \& Edouard, J. L. (2006). Combining ring width, density and stable carbon isotope proxies to enhance the climate signal in tree-rings: an example from the southern French Alps. Climatic Change, 78(2-4), 363-379.

Gagen, M., McCarroll, D., Jalkanen, R., Loader, N. J., Robertson, I., \& Young, G. H. F. (2012). A rapid method for the production of robust millennial length stable isotope tree ring series for climate reconstruction. Global and Planetary Change, 82, 96-103.

Garreaud, R., Lopez, P., Minvielle, M., \& Rojas, M. (2013). Large-scale control on the Patagonian climate. Journal of Climate, 26(1), 215-230. 
Graven, H., Allison, C. E., Etheridge, D. M., Hammer, S., Keeling, R. F., Levin, I., Meijer, H., Rubino, M., Tans, P., Trudinger, C., Vaughn, B., \& White, J. W. (2017). Compiled records of carbon isotopes in atmospheric CO 2 for historical simulations in CMIP6. Geoscientific Model Development, 10(12), 4405-4417.

Grießinger, J., Langhamer, L., Schneider, C., Saß, B. L., Steger, D., Skvarca, P., Braun, M., Meier, W., Srur, A., \& Hochreuther, P. (2018). Imprints of Climate Signals in a 204 Year $\delta 180$ Tree-Ring Record of Nothofagus pumilio From Perito Moreno Glacier, Southern Patagonia $\left(50^{\circ}\right.$ S). Frontiers in Earth Science, 6, 27.

Grissino-Mayer, H. D. (2001). Evaluating crossdating accuracy: a manual and tutorial for the computer program COFECHA. Tree-Ring Research, 57, 205-221.

Hartl-Meier, C., Zang, C., Büntgen, U., Esper, J., Rothe, A., Göttlein, A., Dirnbock, T., \& Treydte, K. (2015). Uniform climate sensitivity in tree-ring stable isotopes across species and sites in a mid-latitude temperate forest. Tree Physiology, 35(1), 4-15.

Hendon, H. H., Thompson, D. W., \& Wheeler, M. C. (2007). Australian rainfall and surface temperature variations associated with the Southern Hemisphere annular mode. Journal of Climate, 20(11), 2452-2467.

Hersbach, H., Bell, B., Berrisford, P., Biavati, G., Horányi, A., Muñoz Sabater, J., Nicolas, J., Peubey, C., Radu, R., Rozum, I., Schepers, D., Simmons, A., Soci, C., Dee, D., Thépaut, J-N. (2019): ERA5 monthly averaged data on single levels from 1979 to present. Copernicus Climate Change Service (C3S) Climate Data Store (CDS). (Accessed on < DD-MMM-YYYY >), $10.24381 /$ cds.f17050d7

Hessl, A., Allen, K. J., Vance, T., Abram, N. J., \& Saunders, K. M. (2017). Reconstructions of the southern annular mode (SAM) during the last millennium. Progress in Physical Geography, 41(6), 834-849.

Holmes, R. L. (1983). Computer-assisted quality control in tree-ring dating and measurement.

IAEA/WMO (2021). Global Network of Isotopes in Precipitation. The GNIP Database. Accessible at: https://nucleus.iaea.org/wiser

Iannone, R. (2016). splitr: Use the HYSPLIT model from inside R. R package version 0.4.0.9000.

Jeffrey, S.J., Carter, J.O., Moodie, K.B. and Beswick, A.R. (2001). Using spatial interpolation to construct a comprehensive archive of Australian climate data. Environmental Modelling and Software, 16(4), 309-330.

Jones, J. M., Fogt, R. L., Widmann, M., Marshall, G. J., Jones, P. D., \& Visbeck, M. (2009). Historical SAM variability. Part I: Century-length seasonal reconstructions. Journal of Climate, 22(20), 5319-5345.

Keeling, C. D. (1979). The Suess effect: 13Carbon-14Carbon interrelations. Environment International, 2(4-6), 229-300. 
C. D. Keeling, S. C. Piper, R. B. Bacastow, M. Wahlen, T. P. Whorf, M. Heimann, and H. A. Meijer, Exchanges of atmospheric $\mathrm{CO}_{2}$ and ${ }^{13} \mathrm{CO}_{2}$ with the terrestrial biosphere and oceans from 1978 to 2000. I. Global aspects, SIO Reference Series, No. 01-06, Scripps Institution of Oceanography, San Diego, 88 pages, 2001.

Kress, A., Young, G. H., Saurer, M., Loader, N. J., Siegwolf, R. T., \& McCarroll, D. (2009). Stable isotope coherence in the earlywood and latewood of tree-line conifers. Chemical Geology, 268(1-2), 52-57.

Kushner, P. J., Held, I. M., \& Delworth, T. L. (2001). Southern Hemisphere atmospheric circulation response to global warming. Journal of Climate, 14(10), 2238-2249.

Lara, A., \& Villalba, R. (1993). A 3620-year temperature record from Fitzroya cupressoides tree rings in southern South America. Science, 260(5111), 1104-1106.

Lavergne, A., Daux, V., Villalba, R., Pierre, M., Stievenard, M., Vimeux, F., \& Srur, A. M. (2016). Are the oxygen isotopic compositions of Fitzroya cupressoides and Nothofagus pumilio cellulose promising proxies for climate reconstructions in northern Patagonia? Journal of Geophysical Research: Biogeosciences, 121(3), 767-776.

Leavitt, S. W. (2010). Tree-ring C-H-O isotope variability and sampling. Science of the Total Environment, 408(22), 5244-5253.

Libby, L. M., Pandolfi, L. J., Payton, P. H., Marshall, J., Becker, B., \& Giertz-Sienbenlist, V. (1976). Isotopic tree thermometers. Nature, 261(5558), 284-288.

Lim, E. P., Hendon, H. H., Boschat, G., Hudson, D., Thompson, D. W., Dowdy, A. J., \& Arblaster, J. M. (2019). Australian hot and dry extremes induced by weakenings of the stratospheric polar vortex. Nature Geoscience, 12(11), 896-901.

Liu, J., Fu, G., Song, X., Charles, S. P., Zhang, Y., Han, D., \& Wang, S. (2010). Stable isotopic compositions in Australian precipitation. Journal of Geophysical Research:

Atmospheres, 115(D23).

Loader, N. J., Young, G. H. F., McCarroll, D., \& Wilson, R. J. S. (2013). Quantifying uncertainty in isotope dendroclimatology. The Holocene, 23(9), 1221-1226.

Loader, N. J., Young, G. H., McCarroll, D., Davies, D., Miles, D., \& Bronk Ramsey, C. (2020). Summer precipitation for the England and Wales region, 1201-2000 ce, from stable oxygen isotopes in oak tree rings. Journal of Quaternary Science, 35(6), 731-736.

Lukač, L., Mikac, S., Urban, O., Kolář, T., Rybníček, M., Ač, A., Trnka, M., \& Marek, M. V. (2021). Stable Isotopes in Tree Rings of Pinus heldreichii Can Indicate Climate Variability over the Eastern Mediterranean Region. Forests, 12(3), 350.

Mariani, M., \& Fletcher, M. S. (2016). The Southern Annular Mode determines interannual and centennial-scale fire activity in temperate southwest Tasmania, Australia. Geophysical Research Letters, 43(4), 1702-1709. 
Marshall, G. J. (2003). Trends in the Southern Annular Mode from observations and reanalyses. Journal of Climate, 16(24), 4134-4143.

Meier, W. J. H., Aravena, J. C., Jaña, R., Braun, M. H., Hochreuther, P., Soto-Rogel, P., \& Grießinger, J. (2020). A tree-ring $\delta 180$ series from southernmost Fuego-Patagonia is recording flavors of the Antarctic Oscillation. Global and Planetary Change, 195, 103302.

Meneghini, B., Simmonds, I., \& Smith, I. N. (2007). Association between Australian rainfall and the southern annular mode. International Journal of Climatology: A Journal of the Royal Meteorological Society, 27(1), 109-121.

McCarroll, D., \& Pawellek, F. (2001). Stable carbon isotope ratios of Pinus sylvestris from northern Finland and the potential for extracting a climate signal from long Fennoscandian chronologies. The Holocene, 11(5), 517-526.

McCarroll, D., \& Loader, N. J. (2004). Stable isotopes in tree rings. Quaternary Science Reviews, 23(7-8), 771-801.

Moreno-Gutiérrez, C., Dawson, T. E., Nicolás, E., \& Querejeta, J. I. (2012). Isotopes reveal contrasting water use strategies among coexisting plant species in a Mediterranean ecosystem. New Phytologist, 196(2), 489-496.

National Centers for Environmental Prediction/National Weather Service/NOAA/U.S. Department of Commerce. (1994, updated monthly). NCEP/NCAR Global Reanalysis Products, 1948-continuing. Research Data Archive at NOAA/PSL: /data/gridded/data.ncep.reanalysis.html.

O'Donnell, A. J., Allen, K. J., Evans, R. M., Cook, E. R., Trouet, V., \& Baker, P. J. (2016). Wood density provides new opportunities for reconstructing past temperature variability from southeastern Australian trees. Global and Planetary Change, 141, 1-11.

Ogden, J. (1978). Investigations of the dendrochronology of the genus Athrotaxis D. Don (Taxodiaceae) in Tasmania. Tree Ring Bulletin, 38, 1-14.

Pearman, G. I., Francey, R. J., \& Fraser, P. J. B. (1976). Climatic implications of stable carbon isotopes in tree rings. Nature, 260(5554), 771-773.

Porfirio, L. L., Harris, R. M., Lefroy, E. C., Hugh, S., Gould, S. F., Lee, G., Bindoff, N., \& Mackey, B. (2014). Improving the use of species distribution models in conservation planning and management under climate change. PLoS One, 9(11).

Porter, T. J., Pisaric, M. F., Field, R. D., Kokelj, S. V., Edwards, T. W., deMontigny, P., Healy, R. \& LeGrande, A. N. (2014). Spring-summer temperatures since AD 1780 reconstructed from stable oxygen isotope ratios in white spruce tree-rings from the Mackenzie Delta, northwestern Canada. Climate Dynamics, 42(3-4), 771-785.

R Core Team (2013). R: A language and environment for statistical computing. R Foundation for Statistical Computing, Vienna, Austria. http://www.R-project.org/.

Reid, J. B., Hill, R. S., Brown, M. J., \& Hovenden, M. J. (1999). Vegetation of Tasmania. Australian Biological Resources Study, Canberra. 
Roden, J. S., \& Farquhar, G. D. (2012). A controlled test of the dual-isotope approach for the interpretation of stable carbon and oxygen isotope ratio variation in tree rings. Tree Physiology, 32(4), 490-503.

Roig, F. A., Siegwolf, R., \& Boninsegna, J. A. (2006). Stable oxygen isotopes $(\delta 180)$ in Austrocedrus chilensis tree rings reflect climate variability in northwestern Patagonia, Argentina. International Journal of Biometeorology, 51(2), 97-105.

Rozanski, K., Sonntag, C., \& Münnich, K. O. (1982). Factors controlling stable isotope composition of European precipitation. Tellus, 34(2), 142-150.

Scheidegger, Y., Saurer, M., Bahn, M., \& Siegwolf, R. (2000). Linking stable oxygen and carbon isotopes with stomatal conductance and photosynthetic capacity: a conceptual model. Oecologia, 125(3), 350-357.

Speer, J. H. (2010). Fundamentals of Tree-Ring Research. University of Arizona Press, Tucson, Arizona.

Steiger, N. J., Steig, E. J., Dee, S. G., Roe, G. H., \& Hakim, G. J. (2017). Climate reconstruction using data assimilation of water isotope ratios from ice cores. Journal of Geophysical Research: Atmospheres, 122(3), 1545-1568.

Stein, A. F., Draxler, R. R., Rolph, G. D., Stunder, B. J., Cohen, M. D., \& Ngan, F. (2015). NOAA's HYSPLIT atmospheric transport and dispersion modeling system. Bulletin of the American Meteorological Society, 96(12), 2059-2077.

Stokes, M.A. \& Smiley, T.L. (1968). An Introduction to Tree-Ring Dating. University of Arizona Press, Tucson, Arizona.

The NCEP/NCAR 40-Year Reanalysis Project. (1996). BAMS.

Thompson, D. W., \& Wallace, J. M. (2000). Annular modes in the extratropical circulation. Part I: Month-to-month variability. Journal of Climate, 13(5), 1000-1016.

Treydte, K., Boda, S., Graf Pannatier, E., Fonti, P., Frank, D., Ullrich, B., ... \& Gessler, A. (2014). Seasonal transfer of oxygen isotopes from precipitation and soil to the tree ring: source water versus needle water enrichment. New Phytologist, 202(3), 772-783.

Trouet, V., Esper, J., Graham, N. E., Baker, A., Scourse, J. D., \& Frank, D. C. (2009). Persistent positive North Atlantic Oscillation mode dominated the medieval climate anomaly. science, 324(5923), 78-80.

Udy, D. G., Vance, T. R., Kiem, A. S., Holbrook, N. J., \& Curran, M. A. (2021). Links between large-scale modes of climate variability and synoptic weather patterns in the southern Indian Ocean. Journal of Climate, 34(3), 883-899.

Vance, T. R., Roberts, J. L., Plummer, C. T., Kiem, A. S., \& Van Ommen, T. D. (2015). Interdecadal Pacific variability and eastern Australian megadroughts over the last millennium. Geophysical Research Letters, 42(1), 129-137. 
Villalba, R., Lara, A., Masiokas, M. H., Urrutia, R., Luckman, B. H., Marshall, G. J., Mundo, I.A., Christie, D.A., Cook, E.R., Neukom, R., \& Allen, K. (2012). Unusual Southern Hemisphere tree growth patterns induced by changes in the Southern Annular Mode. Nature Geoscience, 5(11), 793-798.

Visbeck, M. (2009). A station-based southern annular mode index from 1884 to 2005. Journal of Climate, 22(4), 940-950.

Waring, R. H., Whitehead, D., \& Jarvis, P. G. (1979). The contribution of stored water to transpiration in Scots pine. Plant, Cell \& Environment, 2(4), 309-317.

Werner, M. (2019). ECHAM5-wiso simulation data - present-day, mid-Holocene, and Last Glacial Maximum. PANGAEA, https://doi.org/10.1594/PANGAEA.902347

Wilson, N., Tickle, P., \& Anderson, H. (2011). 2011 National Elevation Data Audit. Geoscience Australia, Canberra. http://pid.geoscience.gov.au/dataset/ga/72622

Zang, C., \& Biondi, F. (2015). treeclim: an R package for the numerical calibration of proxy-climate relationships. Ecography, 38(4), 431-436.

Zhang, Z. Y., Gong, D. Y., \& He, X. Z. (2010). Statistical reconstruction of the Antarctic Oscillation index based on multiple proxies. Atmos. Oceanic Sci. Lett. 3(5), 283-287. 


\section{Appendix}
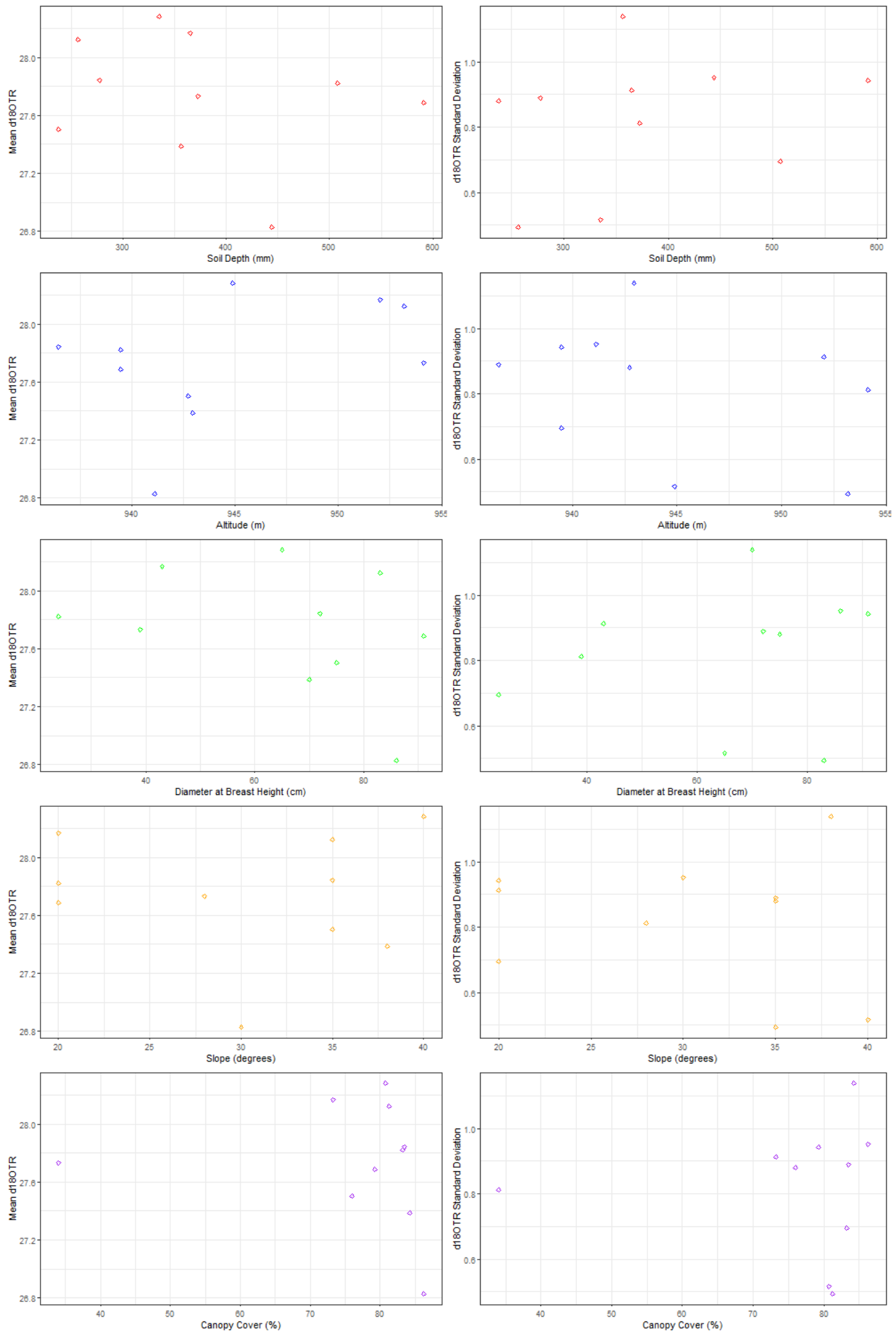

Appendix 1: Plots of mean $\delta^{18} O_{T R}$ and $\delta^{18} O_{T R}$ standard deviation by tree against site conditions at each tree (soil depth, altitude, diameter at breast height, slope, and canopy cover). No significant relationships exist between mean $\delta^{18} O_{T R}$ or $\delta^{18} O_{T R} s^{5}{ }^{2}$ dard deviation and the site conditions I measured $(n=10)$. 